NBER WORKING PAPER SERIES

\title{
ARE ASSET PRICE GUARANTEES USEFUL \\ FOR PREVENTING SUDDEN STOPS? \\ A QUANTITATIVE INVESTIGATION OF THE \\ GLOBALIZATION HAZARD-MORAL HAZARD TRADEOFF
}

\author{
Ceyhun Bora Durdu \\ Enrique G. Mendoza \\ Working Paper 11178 \\ http://www.nber.org/papers/w11178
}

\author{
NATIONAL BUREAU OF ECONOMIC RESEARCH \\ 1050 Massachusetts Avenue \\ Cambridge, MA 02138 \\ March 2005
}

Work on this project began while Mendoza was a visiting scholar at the Research Department of the InterAmerican Development Bank. Comments and suggestions by Guillermo Calvo, Reuven Glick, Olivier Jeanne, Urban Jermann, Alejandro Izquierdo, Katherine Smith, Linda Tesar and Diego Valderrama are gratefully acknowledged. The views expressed herein are those of the author(s) and do not necessarily reflect the views of the National Bureau of Economic Research.

(C) 2005 by Ceyhun Bora Durdu and Enrique G. Mendoza. All rights reserved. Short sections of text, not to exceed two paragraphs, may be quoted without explicit permission provided that full credit, including (C) notice, is given to the source. 
Are Asset Price Guarantees Useful for Preventing Sudden Stops?: A Quantitative Investigation of the Globalization Hazard-Moral Hazard Tradeoff

Ceyhun Bora Durdu and Enrique G. Mendoza

NBER Working Paper No. 11178

March 2005

JEL No. F41, F32, E44, D52

\begin{abstract}
$\underline{\text { ABSTRACT }}$
The globalization hazard hypothesis maintains that the current account reversals and asset price collapses observed during 'Sudden Stops' are caused by global capital market frictions. A policy implication of this view is that Sudden Stops can be prevented by offering global investors price guarantees on emerging markets assets. These guarantees, however, introduce a moral hazard incentive for global investors, thus creating a tradeoff by which price guarantees weaken globalization hazard but strengthen international moral hazard. This paper studies the quantitative implications of this tradeoff using a dynamic stochastic equilibrium asset-pricing model. Without guarantees, distortions induced by margin calls and trading costs cause Sudden Stops driven by Fisher's debt-deflation mechanism. Price guarantees prevent this deflation by introducing a distortion that props up foreign demand for assets. Non-state-contingent guarantees contain Sudden Stops but they are executed often and induce persistent asset overvaluation. Guarantees offered only in highdebt states are executed rarely and prevent Sudden Stops without persistent asset overvaluation. If the elasticity of foreign asset demand is low, price guarantees can still contain Sudden Stops but domestic agents obtain smaller welfare gains at Sudden Stop states and suffer welfare losses on average in the stochastic steady state.
\end{abstract}

Ceyhun Bora Durdu

Department of Economics

University of Maryland

College Park, MA 20742

durdu@econ.bsos.umd.edu
Enrique G. Mendoza

Department of Economics

University of Maryland

College Park, MD 20742

and NBER

mendozae@econ.umd.edu 


\section{Introduction}

The Sudden Stop phenomenon of emerging markets crises is characterized by three stylized facts: a sudden reversal of private capital inflows and current account deficits, a collapse in production and private absorption, and large relative price corrections in domestic goods prices and asset prices. A large fraction of the literature on this subject is based on a hypothesis that Calvo (2002) labeled "globalization hazard." According to this hypothesis, world capital markets are inherently imperfect, and hence prone to display contagion and overreaction in the determination of asset positions and prices relative to levels consistent with "fundamentals" (see Arellano and Mendoza (2003) for a short survey of this literature). This argument suggests that an international financial organization (IFO) could help prevent Sudden Stops by offering global investors ex-ante price guarantees on the emerging-markets asset class. Calvo put forward a formal proposal for setting up this facility and compared it with other arrangements that propose ex-post price guarantees for global investors (including the IMF's Contingent Credit Line and the proposal put forward by Lerrick and Meltzer (2003)).

Ex-ante price guarantees aim to create an environment in which asset prices can be credibly expected to remain above the crash levels that trigger Sudden Stops driven by globalization hazard. Calvo views this facility as kin to an open-markets operation facility: it would exchange a liquid, riskless asset (e.g., U.S. T-bills) for an index of emerging markets assets whenever the value of the index falls by a certain amount, and would re-purchase the riskless asset when the index recovers. The optimal response of market participants would incorporate their expectations that these guarantees would be executed if a systemic fire sale were to make asset prices crash, and hence the price guarantees could rule out rational expectations equilibria in which Sudden Stops occur. If globalization hazard is the only cause of Sudden Stops, and if the support of the probability distribution of the shocks that can cause them is known (i.e., if there are no truly "unexpected" shocks), the facility would rarely trade.

A potentially important drawback of ex-ante price guarantees is that they introduce moral hazard incentives for global investors. Everything else the same, the introduction of the guarantees increases the foreign investors' demand for emerging markets assets, since the downside risk of holding these assets is transferred to the IFO providing the guarantees. This can be a serious drawback because a similar international moral hazard argument has been forcefully put forward as a competing explanation of Sudden Stops, and has been used to propose major reforms to the international financial system (see the Meltzer Commission report and the article by Lerrick and Meltzer (2003)). ${ }^{1}$

Proponents of the international moral hazard view argue that Sudden Stops are induced by excessive indebtedness of emerging economies driven by the expectation of global investors that IFOs will bail out countries in financial difficulties. Based on this premise, Lerrick and

\footnotetext{
${ }^{1}$ Part of the literature on Sudden Stops focuses on domestic moral hazard problems caused by government guarantees offered to domestic agents (see, for example, Krugman (2000)). This paper focuses instead on Sudden Stops triggered by globalization hazard, and on the tradeoff between this hazard and the international moral hazard created by offering price guarantees to global investors.
} 
Meltzer (2003) proposed the use of ex-post price guarantees to be offered by an IFO to anchor the orderly resolution of a default once it has been announced and agreed to with the IFO. The IFO would determine the crash price of the defaulted asset and would require the country to commit to re-purchase the asset at its crash price (making the commitment credible by having the IFO commit itself to buy the asset at a negligible discount below the crash price if the country were unable to buy it). If the only cause of Sudden Stops is international moral hazard, the announcement of this arrangement should remove the moral hazard distortion and reduce debt levels, and in practice the arrangement itself would rarely be activated.

The tensions between the globalization hazard and moral hazard hypotheses, and their alternative proposals for using price guarantees, reflect an important tradeoff that ex-ante price guarantees create. On one hand, ex-ante price guarantees could endow IFOs with an effective tool to prevent and manage Sudden Stops driven by frictions affecting international capital markets. On the other hand, ex-ante guarantees could end up making matters worse by strengthening international moral hazard incentives (even if it were true that globalization hazard was the only cause of Sudden Stops in the past).

The globalization hazard-moral hazard tradeoff implies that making the case for ex-ante price guarantees requires their advocates to show that it is possible to design a system of price guarantees such that its benefits, in terms of undoing the distortions induced by financial frictions, outweighs its costs, in terms of inducing moral hazard. The goal of this paper is to study this issue from the perspective of the quantitative predictions of a dynamic, stochastic general equilibrium model of asset pricing and current account dynamics. The model is based on the globalization hazard setup of Mendoza and Smith (2004). This paper adds to their framework an IFO that offers ex-ante guarantees to foreign investors on the asset prices of an emerging economy. We are interested in particular in studying how the guarantees affect asset positions, asset price volatility, business cycle dynamics, and the magnitude of Sudden Stops.

Asset price guarantees have not received much attention in quantitative equilibrium asset pricing theory, with the notable exception of the work by Ljungqvist (2000), and these guarantees have yet to be introduced into the research program dealing with quantitative models of Sudden Stops. The theoretical literature and several policy documents on Sudden Stops have examined various aspects of the globalization hazard and international moral hazard hypotheses separately. From this perspective, one contribution of this paper is that it studies the interaction between these two hypotheses in a unified dynamic equilibrium framework from which we derive quantitative predictions.

The two financial frictions that we borrowed from Mendoza and Smith (2004) to construct a model in which globalization hazard causes Sudden Stops are: (a) a margin constraint on foreign borrowing faced by the agents of an emerging economy, and (b) asset trading costs incurred by foreign securities firms specialized in trading the equity of the emerging economy. ${ }^{2}$ These frictions are intended to represent the collateral constraints and

\footnotetext{
${ }^{2}$ Aiyagari and Gertler (1999) first proposed a closed economy asset-pricing model with these features.
} 
informational frictions that have been widely studied in the Sudden Stops literature (see, for example, Calvo (1998), Izquierdo (2000), Calvo and Mendoza (2000a, 2000b), Caballero and Krishnamurty (2001), Mendoza (2004), Paasche (2001) and Schneider and Tornell (1999)).

The model introduces asset price guarantees in the form of ex-ante guarantees offered to foreign investors on the liquidation price (or equivalently, on the return) of the emerging economy's assets. Thus, these guarantees are kin to a "put option" with minimum return. An IFO offers these guarantees and finances them with a lump-sum tax on foreign investors' profits. Both domestic agents and foreign investors are aware of the IFO's guarantees policy when formulating their optimal plans. Hence, forward-looking equity prices reflect the effects of margin constraints, trading costs and ex-ante price guarantees. The setup of the price guarantees is similar to the one proposed in Ljungqvist's (2000) closed-economy, representativeagent analysis, but framed in the context of what is effectively a two-agent equilibrium assetpricing model with margin constraints and trading costs.

Price guarantees have different implications depending on the level at which they are set. If they are set so low that they are never executed, globalization hazard dominates and the model yields the same Sudden Stop outcomes of the Mendoza-Smith model. If they are set so high that they are always executed, the model yields equilibria highly distorted by international moral hazard. Hence, the interesting range for studying the globalization hazard-moral hazard tradeoff lies between these two extremes. The quantitative analysis shows that guarantees set slightly above the model's "fundamentals" price (by $1 / 2$ to 1 percent) contain the Sudden Stop effects of globalization hazard and virtually eliminate the probability of margin calls in the stochastic steady state. If the guarantee is non-state-contingent, the guarantee is executed often (with a long-run probability of about $1 / 3$ ) and the model predicts persistent overvaluation of asset prices above the prices obtained in a frictionless environment. A guaranteed price set at the same level but offered only at high levels of external debt is executed much less often (with a long run probability below 1/100) and it is equally effective at containing Sudden Stops without inducing persistent asset overvaluation.

Analysis of the normative implications of the model shows that, when the elasticity of foreign demand for domestic assets is high, the guarantees improve domestic welfare measured from initial conditions at a Sudden Stop state, with negligible changes in long-run welfare levels. At the same time, the value of foreign traders' firms measured in a Sudden Stop state falls slightly, while their long-run average rises sharply. In this case the balance tilts in favor of using price guarantees to contain globalization hazard. On the other hand, when the elasticity of foreign demand for domestic assets is low, higher price guarantees are needed to prevent Sudden Stops, and as a result large moral hazard distortions reduce domestic welfare gains at Sudden Stop states and enlarge average welfare losses in the stochastic steady state. In this case, price guarantees can be a misleading policy instrument that yields a short-term improvement in macroeconomic indicators and welfare at the expense of a long-term welfare loss.

The paper is organized as follows. Section 2 presents the model and characterizes the competitive equilibrium in the presence of margin constraints, trading costs and ex-ante price 
guarantees. Section 3 studies key properties of this equilibrium that illustrate the nature of the globalization hazard-moral hazard tradeoff. Section 4 represents the competitive equilibrium as a recursive, rational expectations equilibrium and proposes a solution algorithm. Section 5 conducts the quantitative analysis and Section 6 concludes.

\section{A Model of Globalization Hazard and Price Guarantees}

Consider a small open economy (SOE) inhabited by a representative household that rents out labor and a time-invariant stock of capital to a representative firm. Households can trade the equity of this firm with a representative foreign securities firm specialized in trading the economy's equity, and can also access a global credit market of one-period bonds. In addition, an IFO operates a facility that guarantees a minimum sale price to foreign traders on their sales of the emerging economy's equity. Dividend payments on the emerging economy's equity are stochastic and vary in response to exogenous productivity shocks. Markets of contingent claims are incomplete because trading equity and bonds does not allow domestic households to fully hedge domestic income uncertainty, and the credit market is imperfect because of margin constraints and trading costs.

\subsection{The Emerging Economy}

The representative firm inside the SOE produces a tradable commodity by combining labor $(n)$ and a time-invariant stock of physical capital $(k)$ using a Cobb-Douglas technology: $\exp \left(\varepsilon_{t}\right) F(k, n)$, where $\varepsilon$ is a Markov productivity shock. This firm participates in competitive factor and goods markets taking the real wage $(w)$ as given. Thus, the choice of labor input consistent with profit maximization yields standard marginal productivity conditions for labor demand and the rate of dividend payments $(d)$ :

$$
\begin{aligned}
w_{t} & =\exp \left(\varepsilon_{t}\right) F_{n}\left(k, n_{t}\right) \\
d_{t} & =\exp \left(\varepsilon_{t}\right) F_{k}\left(k, n_{t}\right)
\end{aligned}
$$

The representative household chooses intertemporal sequences of consumption $(c)$, labor supply $(n)$, equity holdings $(\alpha)$, and foreign bond holdings $(b)$ so as to maximize Epstein's (1983) stationary cardinal utility (SCU) function:

$$
U(c, n)=E_{0}\left[\sum_{t=0}^{\infty} \exp \left\{-\sum_{\tau=0}^{t-1} v\left(c_{\tau}-h\left(n_{\tau}\right)\right)\right\} u\left(c_{t}-h\left(n_{t}\right)\right)\right]
$$

This utility function is a time-recursive, Von Neumann-Morgenstern intertemporal utility index with an endogenous rate of time preference. The period utility function $u(\cdot)$ is a standard, concave, twice-continuously differentiable utility function. The function $v(\cdot)$ is the time preference function, which is also concave and twice-continuously differentiable. The argument of both functions is a composite good defined by consumption minus the disutility of labor $c$ $h(n)$, where $h(\cdot)$ is an increasing, convex, continuously-differentiable function. Greenwood, Hercowitz and Huffman (1988) introduced this composite good as a way to eliminate the wealth effect on labor supply. As in Mendoza and Smith (2004), this property of preferences, together with conditions (1) and (2), separates the determination of equilibrium wages, dividends, labor and output from the equilibrium allocations of consumption, saving and portfolio choice. 
The endogenous rate of time preference of the SCU function introduces an "impatience effect" on the marginal utility of date-t consumption by which changes in $c_{t}$ alter the subjective discount rate applied to future utility flows. Epstein showed that the conditions required for SCU to be consistent with consumption smoothing limit this impatience effect. Utility functions with endogenous impatience are commonly used in models of small open economies to obtain well-defined long-run equilibria for holdings of foreign assets in which the exogenous world interest rate equals the rate of time preference (see for example Obstfeld (1981) or Mendoza (1991)). ${ }^{3}$ As Section 3 shows, in models with financial frictions these preferences are also critical for supporting long-run equilibria in which credit constraints bind.

The household maximizes lifetime utility subject to the following budget constraint:

$$
c_{t}=\alpha_{t} k d_{t}+w_{t} n_{t}+q_{t}\left(\alpha_{t}-\alpha_{t+1}\right) k-b_{t+1}+b_{t} R
$$

where $\alpha_{t}$ and $\alpha_{t+1}$ are beginning- and end-of-period shares of capital owned by households, $q_{t}$ is the price of equity, and $R$ is the world real interest rate (which is kept constant for simplicity).

International loan contracts incorporate a collateral constraint in the form of a margin clause by which the stock of foreign debt of the small open economy cannot exceed the fraction $\kappa$ of the market value of the SOE's equity holdings:

$$
b_{t+1} \geq-\kappa q_{t} \alpha_{t+1} k, \quad 0 \leq \kappa \leq 1
$$

Margin clauses of this form are widely used in international capital markets. In some instances they are imposed by regulators with the aim of limiting the exposure of financial intermediaries to idiosyncratic risk in lending portfolios, but they are also widely used by investment banks and other lenders as a mechanism to manage default risk (they can take the form of explicit margin clauses linked to the value of specific securities offered as collateral, or implicit margin requirements linked to the volatility of returns of an asset class or subclass as those implied by value-at-risk collateralization). Margin clauses are a particularly effective collateral constraint (compared to constraints like the well-known Kiyotaki-Moore constraint that limits debt to the discounted liquidation value of assets one period ahead) because: (a) custody of the securities that constitute the collateral is surrendered at the time the credit contract is entered and (b) margin calls to make up for shortfalls in the market value of the collateral are automatic once the value of the securities falls below the contracted value.

Households in the small open economy also face a short-selling constraint in the equity market: $\alpha_{t+1} \geq \chi$ with $-\infty<\chi<1$ for all $t$. This constraint is necessary in order to make the margin constraint non-trivial. Otherwise, any borrowing limit in the bond market implied by a binding margin constraint could always be undone by taking a sufficiently short equity position.

\subsection{The Foreign Securities Firm, the IFO 8 the Price Guarantees}

The representative foreign securities firm obtains funds from international investors and specializes in investing them in the SOE's equity. The securities firm maximizes its net present value discounted at the stochastic discount factor relevant for its international clients (i.e., the

\footnotetext{
${ }^{3}$ Arellano and Mendoza (2003) provide further details and a short survey of the literature on this issue.
} 
world interest rate). Thus, the foreign traders' problem is to choose a sequence of equity holdings $\alpha_{t+1}{ }^{*}$, for $t=1, \ldots, \infty$, so as to maximize:

$$
D=E_{0}\left[\sum_{t=0}^{\infty} R^{-t} \pi_{t}\right], \quad \pi_{t} \equiv k\left[\alpha_{t}^{*} d_{t}-\left(q_{t} \alpha_{t+1}^{*}-\max \left(q_{t}, \tilde{q}_{t}\right) \alpha_{t}^{*}\right)-q_{t}\left(\frac{a}{2}\right)\left(\alpha_{t+1}^{*}-\alpha_{t}^{*}+\theta\right)^{2}-T_{t}^{*}\right] .
$$

The total net return of the foreign securities firm $\left(\pi_{t}\right)$ is the sum of: (a) dividend earnings on current equity holdings $\left(k \alpha_{t}^{*} d_{t}\right)$, minus (b) the value of equity trades, which is the difference between equity purchases $q_{t} k \alpha_{t+1}{ }^{*}$ minus equity sales $\max \left(q_{t}, \tilde{q}_{t}\right) k \alpha_{t}{ }^{*}$ executed at either the market price $q_{t}$ or the guaranteed price $\tilde{q}_{t}$, whichever is greater, minus (c) trading costs, which include a term that depends on the size of trades $\left(\alpha_{t+1}{ }^{*}-\alpha_{t}{ }^{*}\right)$ and a recurrent trading cost $(\theta)$, minus (d) lump sum taxes paid to the IFO $\left(k T_{t}^{*}\right)$. Trading costs are specified in quadratic form, as in some of the literature on equilibrium asset pricing models with trading costs, so $a$ is a standard adjustment-cost coefficient.

The IFO buys equity from the foreign traders at the guaranteed price and sells it at the equilibrium price. Thus, the IFO's budget constraint is:

$$
T_{t}^{*}=\max \left(0,\left(\tilde{q}_{t}-q_{t}\right) \alpha_{t}^{*}\right)
$$

If the guarantee is not executed, the tax is zero. If the guarantee is executed, the IFO sets the lump-sum tax to match the value of the executed guarantee (i.e., the extra income that foreign traders earn by selling equity to the IFO instead of selling it in the equity market). Since the return on equity is $R_{t}^{q} \equiv\left[d_{t}+q_{t}\right] / q_{t-1}$, the IFO's offer to guarantee the date-t price implies a guaranteed return on the emerging economy's equity $\tilde{R}_{t}^{q}=\left[\tilde{q}_{t}+d_{t}\right] / q_{t-1}$.

\subsection{Equilibrium}

A competitive equilibrium is given by stochastic sequences of prices $\left[w_{t}, d_{t}, q_{t}\right]_{t=0}^{\infty}$ and

allocations $\left[c_{t}, n_{t}, b_{t+1}, \alpha_{t+1}, \alpha_{t+1}^{*}, T_{t}^{*}\right]_{t=0}^{\infty}$ such that: (a) households maximize the utility function (3) subject to the constraints (4) and (5) and the short-selling constraint, taking prices, wages and dividends as given, (b) domestic firms maximize profits so that equations (1) and (2) hold, taking wages and dividends as given, (c) foreign traders maximize (6) taking the price of equity, the price guarantees and lump-sum taxes as given, (d) the budget constraint of the IFO in equation (7), holds and (e) the equity market clears (i.e., $\alpha_{t}+\alpha_{t}{ }^{*}=1$ for all $t$ ).

\section{Characterizing the Globalization Hazard-Moral Hazard Tradeoff}

The tradeoff between the globalization hazard introduced by the distortions that margin constraints and trading costs create and the moral hazard introduced by distortions due to price guarantees can be illustrated with the optimality conditions of the competitive equilibrium. Consider the first-order conditions of the domestic household's maximization problem:

$$
\begin{gathered}
U_{C_{t}}(c, n)=\lambda_{t} \\
h^{\prime}\left(n_{t}\right)=w_{t} \\
q_{t}\left(\lambda_{t}-\eta_{t} \kappa\right)=E_{t}\left[\lambda_{t+1}\left(d_{t+1}+q_{t+1}\right)\right]+v_{t} \\
\lambda_{t}-\eta_{t}=E_{t}\left[\lambda_{t+1} R\right]
\end{gathered}
$$

$U_{c_{t}}(c, n)$ is the derivative of the SCU function with respect to $c_{t}$ (which includes the impatience effect), and $\lambda_{t}, \eta_{t}$ and $v_{t}$ are the Lagrange multipliers on the budget constraint, the margin constraint, and the short-selling constraint respectively. 
Condition (8) has the standard interpretation: at equilibrium, the marginal utility of wealth equals the lifetime marginal utility of consumption. Condition (9) equates the marginal disutility of labor with the real wage. This is the case because the Greenwood-HercowitzHuffman composite good implies that the marginal rate of substitution between $c_{t}$ and $n_{t}$ is equal to the marginal disutility of labor $h^{\prime}\left(n_{t}\right)$, and thus is independent of $c_{t}$. It follows from this result that condition (9) together with (1) and (2) determine the equilibrium values of $n_{t}, w_{t}$ and $d_{t}$ as well as the equilibrium level of output. These "supply-side" solutions are independent of the dynamics of consumption, saving, portfolio choices and equity prices, and are therefore also independent of the distortions induced by financial frictions and price guarantees.

The neutrality of the "supply side" of the domestic economy with respect to the financial frictions follows from admittedly strong assumptions but it simplifies significantly the solution of the model by separating the equilibrium path of dividends from the saving and portfolio decisions. Mendoza (2004) studies the business cycle implications of margin constraints in a small-open-economy model with endogenous investment in which financial frictions affect dividends, investment and the Tobin $\mathrm{Q}$, but abstracting from international equity trading.

Conditions (10) and (11) are Euler equations for the accumulation of equity and bonds respectively. As in Mendoza and Smith (2004), these conditions can be combined to derive expressions for the forward solution of equity prices and the excess return on equity from the perspective of the emerging economy. The forward solution for equity prices is:

$$
q_{t}=E_{t}\left(\sum_{i=0}^{\infty}\left[\prod_{j=0}^{i}\left(1-\frac{\eta_{t+j}}{\lambda_{t+j}} \kappa\right)^{-1}\right] M_{t+1+i} d_{t+1+i}\right)
$$

where $M_{t+1+i} \equiv \lambda_{t+1+i} / \lambda_{t}$, for $\mathrm{i}=0, \ldots, \infty$, is the marginal rate of substitution between $c_{t+1+i}$ and $c_{t}$. The excess return on domestic equity is:

$$
E_{t}\left[R_{t+1}^{q}\right]-R=\frac{\eta_{t}(1-\kappa)-\frac{v_{t}}{q_{t}}-C O V_{t}\left(\lambda_{t+1}, R_{t+1}^{q}\right)}{E_{t}\left[\lambda_{t+1}\right]}
$$

Given these results, the forward solution for equity prices can also be expressed as:

$$
q_{t}=E_{t}\left(\sum_{i=0}^{\infty}\left[\prod_{j=0}^{i}\left(E_{t}\left[R_{t+1+j}^{q}\right]\right)^{-1}\right] d_{t+1+i}\right)
$$

Expressions (12)-(14) show the direct and indirect effects of margin calls on the demand for equity of domestic agents, and thus on their valuation of equity and excess returns. The direct effect of a date- $t$ margin call is represented by the term $\eta_{t}(1-\kappa)$ in (13), or the term $\eta_{t} \kappa$ in (12): When a margin call occurs, domestic agents "fire sale" equity in order to meet the call and satisfy the borrowing constraint. Everything else the same, this effect lowers the date- $t$ equity price and increases the expected excess return for $t+1$. The indirect effect of the margin call is reflected in the fact that a binding borrowing limit makes "more negative" the co-variance between the marginal utility of consumption and the rate of return on equity (since a binding borrowing limit hampers the households' ability to smooth consumption). These direct and indirect effects increase the rate at which future dividends are discounted in the domestic agents' valuation of asset prices, and thus reduce their demand for equity. Interestingly, the 
date- $t$ equity price along the domestic agents' demand curve is reduced by a margin constraint that is binding at date $t$ or by any expected binding margin constraint in the future. As a result, equity prices and the domestic demand for equity can be distorted by the margin requirements even in periods in which the constraint does not bind.

In a world with frictionless asset markets, domestic agents facing margin calls could sell assets in a perfectly-competitive market in which the world demand for the emerging economy's assets is infinitely elastic at the level of the fundamentals price. Margin calls would trigger portfolio reallocation effects without any price movements. However, in the presence of frictions that make the world demand for the emerging economy's assets less than infinitely elastic, the equilibrium asset price falls. Since households were already facing margin calls at the initial price, this price decline tightens further the margin constraint triggering a new round of margin calls. This downward spiral in equity prices is a variant of Fisher's debt-deflation mechanism, which magnifies the direct and indirect effects of the margin constraint.

The world demand for assets of the emerging economy is less than infinitely elastic because of the trading costs that foreign traders incur. Define the conditional expected value of the stream of dividends discounted at the world interest rate as the "fundamentals" price $q_{t}{ }^{f} \equiv E_{t}\left(\sum_{i=0}^{\infty} R^{-(t+1+i)} d_{t+1+i}\right)$. The first-order condition for the optimization problem of foreign traders implies then that the traders' asset demand function is:

$$
\left(\alpha_{t+1}^{*}-\alpha_{t}^{*}\right)=\frac{1}{a}\left(\frac{q_{t}^{f}}{q_{t}}-1+\frac{E_{t}\left[\sum_{i=1}^{\infty} R^{-(t+i)}\left(\max \left(q_{t+i}, \tilde{q}_{t+i}\right)-q_{t+i}\right)\right]}{q_{t}}\right)-\theta
$$

The foreign traders' demand for the emerging economy's assets is an increasing function of: (a) the percent deviation of $q_{t}^{f}$ relative to $q_{t}$ (with an elasticity equal to $1 / a$ ) and (b) the expected present discounted value of the "excess prices" induced by the price guarantees in percent of today's equity price. The first effect reflects the influence of the per-trade trading costs. If $a=0$ and there are no price guarantees, the foreign traders' demand function is infinitely elastic at $q^{f}$. The second effect is the international moral hazard effect of the guarantees, which acts as a demand shifter on the foreign traders' demand function. Foreign traders that expect price guarantees to be executed at any time in the future have a higher demand for domestic assets at date $t$ than they would in a market without guarantees. The recurrent trading costs are also a demand shifter (the foreign traders' demand function is lower the higher is $\theta$ ).

Putting together the previous results, the tradeoff between globalization hazard and international moral hazard can be summarized as follows. Suppose the date- $t$ asset price in a market without margin constraints and without price guarantees is determined at the intersection of the domestic agents' and foreign traders' demand curves ( $H H$ and FF respectively) at point $\mathrm{A}$ in Figure 1.

The demand function of foreign traders is simply equation (15), shown in Figure 1 as a linear function for simplicity and as an upward-slopping curve because the horizontal axis 
measures $\alpha$, which is the complement of $\alpha^{*}$. This FF curve is relatively flat to approximate a situation with low per-trade costs. There is no closed-form solution for $H H$, so the curve depicted is intended only to facilitate intuition. $H H$ is shown as an downward-slopping curve but, since domestic agents respond to wealth, intertemporal-substitution and portfoliocomposition effects in choosing their equity holdings, $H H$ can be downward or upward slopping depending on which effect dominates.

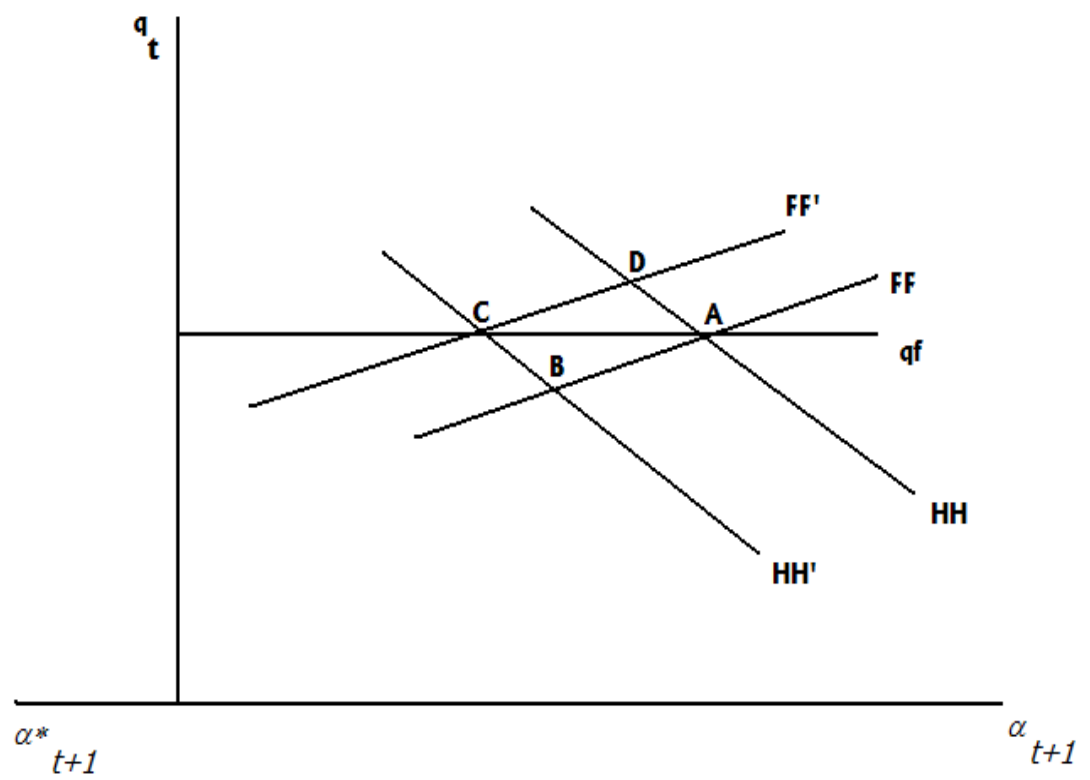

Figure 1.

Suppose that a margin call hits domestic agents because an adverse shock hits the economy when their debt is sufficiently high relative to the value of their assets. As a result, $H H$ shifts to $H H^{\prime}$. In Figure 1, $H H^{\prime}$ represents the "final" demand function, including the magnification effect of the Fisherian debt-deflation mechanism. Without price guarantees, the date- $t$ equilibrium price would fall to point B. This is the "Sudden Stop scenario," in which margin calls result in lower asset prices and reversals in consumption and the current account. Enter now an IFO that sets a price guarantee higher than the market price at B. The international moral hazard effect shifts the foreign traders' demand curve to $F F^{\prime}$ and the new date- $t$ market price is determined at point $\mathrm{C}$, which yields the fundamentals price. The scenario depicted here is an ideal one in which the IFO is assumed to know exactly at what level to set the guaranteed price so as to stabilize the market price at the fundamentals level. If the guarantee is "too low" (i.e., below the price at B) it would have no effect on the Sudden Stop equilibrium price, and thus price guarantees would be irrelevant. If the guarantee is "too high" it could lead to a price higher than the fundamentals price with the "overpricing" even larger than the "underpricing" that occurs at B. Hence, ex-ante price guarantees do not necessarily reduce the volatility of asset prices (as the numerical analysis of Ljungqvist (2000) showed). 
In Figure 1, the equilibrium with margin constraints, trading costs and price guarantees at $\mathrm{C}$ is one in which foreign traders own more equity than in the absence of price guarantees at B. This can still allow domestic agents to support higher debt in the bond market, as long as the value of their equity increases (i.e., as long as the increase in $q_{t}$ offsets the reduction in $\alpha_{t+1}$ ).

If the $H H$ and $H H^{\prime}$ curves were upward sloping, the moral hazard effect would still prop up the foreign traders' asset demand function, but in the equilibrium with price guarantees, domestic agents would end up owning more equity relative to the equilibrium without price guarantees. In this case, this higher level of domestic equity holdings also means that the domestic economy's debt would be higher than in the absence of the guarantees when the margin constraint binds. Thus, the model can predict that price guarantees offered to foreign traders lead to excessive holdings of equity and excessive borrowing by domestic agents.

From the perspective of the dynamic stochastic general equilibrium model, Figure 1 is a partial equilibrium snapshot of the date- $t$ asset market. The forward-looking behavior of domestic households and foreign traders implies that changes that affect the date- $t$ asset market spillover into the market outcomes at other dates and vice versa. For example, the price guarantee may not be in force at $t$ but the expectation of executing future price guarantees will shift upward the $F F$ curve at $t$. Similarly, the margin constraint may not bind at $t$, but the expectation of future margin calls is enough to shift the date- $t H H$ curve. Given the lack of closed-form solutions for equilibrium allocations and prices, the only way to study the effects of price guarantees on the dynamics of consumption, the current account, asset holdings, and asset prices is by exploring the model's quantitative implications via numerical simulation.

\section{Recursive Equilibrium and Solution Method}

In the recursive representation of the equilibrium, the state variables are the current holdings of assets and bonds in the emerging economy, $\alpha$ and $b$, and the realizations of productivity shocks $\varepsilon$. The state space of asset positions spans the discrete grid of NA nodes $\mathrm{A}=\left\{\alpha_{1}<\alpha_{2}<\ldots<\alpha_{N A}\right\}$ with $\alpha_{1}=\chi$, and the state space of bonds spans the discrete grid of NB nodes $\mathrm{B}=\left\{b_{1}<b_{2}<\ldots<b_{N B}\right\}$. The endogenous state space is defined by the discrete set $Z=\mathrm{A} \times \mathrm{B}$ of $\mathrm{NA} \times \mathrm{NB}$ elements. Productivity shocks follow a stationary, two-point Markov chain with realizations $\mathrm{E}=\left\{\varepsilon_{L}<\varepsilon_{H}\right\}$. Equilibrium wages, dividends, labor and output are determined by solving the supply-side system given by equations $(1),(2),(9)$ and the production function. The solutions are given by functions that depend only on $\varepsilon: w(\varepsilon), d(\varepsilon), n(\varepsilon)$ and $F(\varepsilon)$.

Assume that foreign traders and domestic agents take as given a continuous, nonnegative asset pricing function $\hat{q}(\alpha, b, \varepsilon): E \times Z \rightarrow R^{+}$. For a given pair of conjectured decision rules for assets and bonds, $\hat{\alpha}^{\prime}(\alpha, b, \varepsilon), \hat{b}^{\prime}(\alpha, b, \varepsilon): E \times Z \rightarrow R$, the conjectured pricing function must satisfy $q^{\min }(\alpha, b, \varepsilon) \leq \hat{q}(\alpha, b, \varepsilon) \leq q^{\max }(\alpha, b, \varepsilon)$, where:

$$
\begin{gathered}
q^{\min }(\alpha, b, \varepsilon)=\left[q^{f}(\varepsilon)+G(\alpha, b, \varepsilon)\right] /[1+a(\alpha-\chi+\theta)] \\
q^{\max }(\alpha, b, \varepsilon)=\left[q^{f}(\varepsilon)+G(\alpha, b, \varepsilon)\right] /\left[1+a\left(\alpha-\alpha_{N A}+\theta\right)\right]
\end{gathered}
$$

and $G(\alpha, b, \varepsilon)$ represents the expected present discounted value of "excess prices" induced by the price guarantees and the conjectured pricing function and decision rules. The prices in (16) and 
(17) are maximum and minimum prices along the foreign traders' demand curve. These bounds of the pricing function follow from the fact that when domestic agents hit either $\chi$ or $\alpha_{N A}$, the foreign traders are at the "short side" of the market.

The recursive equilibrium can be characterized in one of the two ways described in Mendoza and Smith (2004), modified to include the effect of the price guarantees. One approach iterates on the asset pricing function "outside" the optimization problem of the SOE. This approach uses the conjectured pricing function, the foreign trader's demand function and the market-clearing condition in the asset market to create a conjectured law of motion for equity holdings, and solves a dynamic programming problem for the SOE in which bond holdings are the only endogenous state given this law of motion and the conjectured pricing function. This dynamic programming problem yields optimal consumption plans and these plans are then used to compute an "actual" pricing function. The "actual" and conjectured pricing functions are used to create a new conjectured pricing function with a Gauss-Siedel rule, and the process is repeated until the conjectured and actual pricing functions satisfy a convergence criterion.

The drawback of this method is that convergence of pricing function iterations is not achieved via a contraction mapping property like that of the Bellman equation. Instead, pricing function iterations seek "stable convergence" of excess supply or demand to market-clearing prices in all points of the state space starting from an arbitrary initial pricing function. This creates two problems. First, convergence is slow because Gauss-Siedel updates of price conjectures need to use adaptive successive overrelaxation to prevent price iterations from producing the classic problem of unstable "hog" cycles (by which price iterations diverge away from market-clearing prices instead of converging to them). As a result, solutions based on this method can take several hours to compute. Second, the final pricing function generally retains higher margins of error than those produced by value function iterations.

The second method represents the equilibrium of the model in recursive form using a "quasi-planning problem" in which the contraction-mapping property of the Bellman equation is exploited to compute equilibrium prices faster and without error. The quasi-planning-problem approach starts with a conjecture for the expected present value of "excess prices" $\hat{G}(\alpha, b, \varepsilon)$. Given this conjecture, the optimal plans of domestic agents are represented as the solution to the following dynamic programming problem:

$$
V(\alpha, b, \varepsilon)=\max _{\alpha^{\prime}, b^{\prime} \in \mathrm{A} \times \mathrm{B}}\left\{u(c-h(n(\varepsilon)))+\exp (-v(c-h(n(\varepsilon)))) E\left[V\left(\alpha^{\prime}, b^{\prime}, \varepsilon^{\prime}\right)\right]\right\}
$$

subject to:

$$
\begin{gathered}
c=\alpha k d(\varepsilon)+w(\varepsilon) n(\varepsilon)+\frac{q^{f}(\varepsilon)+\hat{G}(\alpha, b, \varepsilon)}{1+a \theta+a\left(\alpha-\alpha^{\prime}\right)} k\left(\alpha-\alpha^{\prime}\right)-b^{\prime}+b R \\
b^{\prime} \geq-\kappa \frac{q^{f}(\varepsilon)+\hat{G}(\alpha, b, \varepsilon)}{1+a \theta+a\left(\alpha-\alpha^{\prime}\right)} \alpha^{\prime} k
\end{gathered}
$$

In this formulation, domestic agents choose equity and bond positions and equity prices are displaced with the prices along the demand curve of foreign traders by imposing market clearing in the equity market and solving for the equity prices implied by equation (15). 
Once the above dynamic programming problem is solved, the resulting optimal plans for equity holdings are plugged into equation (15) to derive the "actual" asset pricing function for the given conjecture $\hat{G}(\alpha, b, \varepsilon)$. The decision rules for bonds and equity, the guaranteed prices, and this "actual" pricing function are then used to solve for the "actual" $G(\alpha, b, \varepsilon)$ function (i.e., the function that returns the expected present discounted value of excess prices conditional on any initial triple $(\alpha, b, \varepsilon))$. The conjectured and actual $G$ functions are then combined to create a new conjecture using a standard Gauss-Siedel rule and the procedure starts again with the Bellman equation (18). The process is repeated until the actual and conjectured $G$ functions converge, so that the function $\hat{G}(\alpha, b, \varepsilon)$ that is taken as given in the dynamic programming problem is consistent with the function $G(\alpha, b, \varepsilon)$ implied by the asset pricing function and decision rules that are endogenous outcomes of that problem.

The drawback of this quasi-planning-problem method is that in principle it treats the emerging economy as a Stackelberg leader that internalizes the demand function of foreign traders. Mendoza and Smith (2004) show, however, that the only deviation from the competitive equilibrium conditions introduced by this Stackelberg-leader feature reduces to a distortion that appears as a multiple of the return on equity in the marginal benefit of equity purchases by domestic agents. Thus, the equilibrium of this quasi-planning problem is equivalent to a competitive equilibrium for a variant of the model with a proportional tax or subsidy on asset returns, with tax revenues rebated as a lump-sum transfer. Mendoza and Smith show that whether the distortion is a tax or a subsidy depends on how much date- $t$ and date- $t+1$ equity prices vary with the optimal choice of $\alpha_{t+1}$ along the foreign traders' demand curve, which in turn depends on the size of $a$ (i.e., on the price elasticity of this demand function).

We face therefore a choice between a method that solves the competitive equilibrium with error in the asset pricing function and a method that computes prices without error but does so by introducing a tax-like distortion on equity returns earned by domestic agents. In the simulations of the next Section we use a baseline value of $a=0.2$ and consider also $a=2$ as part of a sensitivity analysis. The maximum absolute values of the distortion produced by the quasiplanning problem method are equivalent to negligible taxes on asset returns that range between $0.08(0.4)$ and $0.2(0.8)$ percent when $a=0.2(2)$. The average distortion in absolute value is about $0.03(0.3)$ percent in all the simulations with $a=0.2(2)$. Since this method is also considerably faster, we chose to use it instead of the pricing iteration method.

The optimal decision rules obtained after the solution method converges constitute a recursive, rational expectations equilibrium. At this equilibrium, the decision rules determining asset holdings, bond holdings, consumption, labor, wages, dividends, the foreign traders' asset holdings and asset prices are such that: (a) given wages, dividends and asset prices, the policy functions for $c, b^{\prime}, \alpha^{\prime}$ and $n$ maximize household utility and firm profits in the SOE subject to the relevant constraints, ${ }^{4}$ (b) given asset prices and dividends, the choice for $\alpha^{\prime}{ }^{*}$ solves the

\footnotetext{
${ }^{4}$ With the caveat that the Benveniste-Sheinkman equations of the Bellman equation (18) yield an Euler
} equation for equity that includes the tax-like distortion on equity returns. 
maximization problem of foreign traders, (c) the IFO's budget constraint holds and (e) the market-clearing conditions for assets, goods and labor markets hold.

\section{Quantitative Analysis}

The functional forms that represent preferences and technology are the following:

$$
\begin{gathered}
F\left(k, n_{t}\right)=k^{1-\gamma} n_{t}^{\gamma}, \quad 0 \leq \gamma \leq 1 \\
u\left(c_{t}-h\left(n_{t}\right)\right)=\frac{\left[c_{t}-h\left(n_{t}\right)\right]^{1-\sigma}-1}{1-\sigma}, \quad \sigma>1 \\
v\left(c_{t}-h\left(n_{t}\right)\right)=\beta\left[\operatorname{Ln}\left(1+c_{t}-h\left(n_{t}\right)\right)\right], \quad 0<\beta \leq \sigma \\
h\left(n_{t}\right)=\frac{n_{t}^{\delta}}{\delta}, \quad \delta>1
\end{gathered}
$$

$\gamma$ is the labor income share, $\sigma$ is the coefficient of relative risk aversion, $\beta$ is the elasticity of the rate of time preference with respect to $1+c_{t}-h\left(n_{t}\right)$, and $\delta$ determines the wage elasticity of labor supply (which is equal to $1 /(\delta-1)$ ). The condition $0<\beta \leq \sigma$ comes from Epstein (1983).

\subsection{Deterministic Steady State and Calibration to Mexican Data}

The calibration strategy differs markedly from the one in Mendoza and Smith (2004).

They normalize the capital stock to $k=1$ and let the steady-state equity price adjust to the value implied by the asset pricing condition given a set of parameter values directly inferred from the data or set to enable the model to match ratios of national accounts statistics. Here, we normalize instead the steady-state equity price so that the capital stock matches the deterministic, steady-state capital stock of a typical RBC-SOE model calibrated to Mexican data (see Mendoza (2004)). The steady state of this RBC-SOE model is a frictionless, neoclassical stationary equilibrium. Calibrating to this frictionless equilibrium helps focus the analysis on the use of price guarantees to prevent Sudden Stops triggered by margin calls that hit the economy only when it is highly leveraged (and hence off the long-run equilibrium).

The risk aversion parameter does not appear in the model's deterministic steady-state conditions. This parameter is set at $\sigma=2$ in line with values often used in RBC-SOE studies. The parameter values that enter into the supply-side system are determined as follows. The labor share is set at $\gamma=0.65$, in line with international evidence on labor income shares. The Mexican average share of labor income in value added in an annual sample for 1988-2001 is 0.34, but values around 0.65 are the norm in several countries and there is concern that the Mexican data may measure inaccurately proprietors income and other forms of labor income (see Mendoza (2004) for details). The real interest rate is set at 6.5 percent, which is also a value widely used in the RBC literature. Since the model is set to a quarterly frequency, this implies $R=1.065^{1 / 4}$. The labor disutility coefficient is set to the same value as in Mendoza and Smith (2004), $\delta=2$, which implies a unitary wage elasticity of labor supply.

As in a typical RBC calibration exercise, the calibration is designed to yield a set of parameter values such that the model's deterministic steady state matches actual averages of the GDP shares of consumption $(s c)$, investment $(s i)$, government purchases $(s g)$ and net exports $(s n x)$. In the Mexican data, these shares are $s c=0.684, s i=0.19, s g=0.092$, and sn $x=0.034$. Since the model does not have investment or government purchases, their combined share $(0.282)$ is treated as exogenous absorption of output equivalent to 28.2 percent of steady- 
state GDP. In the stochastic simulations we keep the corresponding level of these expenditures constant at 28.2 percent of the value obtained for steady-state output in the calibration.

The typical RBC-SOE model features a standard steady-state optimality condition that equates the marginal product of capital net of depreciation with the world interest rate, and a standard law of motion of the capital stock that relates the steady-state investment rate to the steady-state capital-output ratio. Given the values of si, $\gamma, \delta$ and $R$, these two steady-state conditions can be combined to yield values of the depreciation rate (dep) and the capital-output ratio $(s k)$. On an annual basis, the resulting depreciation rate is 7.75 percent and $s k$ is about 2.5 (or 10.08 on a quarterly basis).

In a deterministic steady state of the model of Section 2 in which the credit constraint does not bind and there are no price guarantees, the equity price is $q=q^{f}=d /(R-1)$. Given the RBC-SOE calibration criterion that the steady-state marginal product of capital net of depreciation equals the net world interest rate, $q^{f}$ can be re-written as $F_{k}(k, n) /\left(F_{k}(k, n)\right.$-dep). With the Cobb-Douglas production function this reduces to $q^{f}=(1-\gamma) /(1-\gamma-s i)$. Thus, the requirement that the model's dividend rate must match a typical RBC-SOE calibration implies that the steady-state equity price is determined by si and $\gamma$. With the parameter values set above we obtain $q^{f}=2.19$.

Given the values of $\gamma, \delta, R$, and $q^{f}$ the steady-state solutions for $n, w, k$, and $F(k, n)$ follow from solving the supply-side system conformed by (1), (2), (9) and (21). The resulting steady-state capital stock is $k=79$. By construction, this capital stock is also consistent with the estimated capital-output ratio of 2.5 and the observed Mexican investment rate of 0.19 .

The parameters that remain to be calibrated are the time-preference elasticity coefficient $\beta$ and the financial frictions parameters $a, \theta$ and $\kappa$. The time-preference elasticity coefficient is derived from the consumption Euler equation as follows. In the deterministic stationary state of the model there are no credit constraints and hence the endogenous rate of time preference equals the real interest rate:

$$
\left(1+s c F(k, n)-\frac{n^{\delta}}{\delta}\right)^{\beta}=R
$$

Given the values of $R, \delta, n, F(k, n)$ and $s c$, this condition can be solved for the required value of $\beta$. The solution yields $\beta=0.0118$. The total stock of domestic savings at steady state follows then from the resource constraint as $s=[c-F(k, n)(s i+s g)-w n] /(R-1)=\alpha q^{f} k+b$.

$\mathrm{Up}$ to this point the calibration followed the typical RBC-SOE deterministic calibration exercise. A problem emerges, however, when we try to determine the composition of the savings portfolio because the allocation of savings across bonds and equity is undetermined. Any portfolio $(\alpha, b) \in \mathrm{A} \times \mathrm{B}$ is consistent with the RBC-SOE deterministic steady state as long as it supports the unique steady-state level of savings (i.e., $\alpha q^{f} k+b=s$ ) and the margin and shortselling constraints do not bind $\left(b>-\kappa \alpha q^{f} k\right.$ and $\left.\alpha>\chi\right)$. Moreover, given the values of $s, q^{f}$ and $k$ implied by the calibration, it follows from the definition of savings that there is only a small subset of portfolios in which the economy borrows in the bond market (i.e., portfolios with $b<0$ ) 
in the set of multiple steady-state portfolios. Debt portfolios require $\alpha>0.9$. If domestic agents own less than 90 percent of $k$, their steady-state bond position is positive and grows larger the smaller is $\alpha$. This also implies that it will take low values of $\kappa$ to make the margin constraint bind. In particular, setting the upper bound of $\alpha$ at 100 percent, it takes $\kappa \leq 0.10$ for the margin constraint to bind for at least some of the multiple steady-state pairs of $(\alpha, b)$. These low values of $\kappa$ can be justified by considering that the margin constraint represents the fraction of domestic capital that is useful collateral for external debt. Several studies in the Sudden Stops literature provide arguments to suggest that this fraction is small (see, for example, Caballero and Krishnamurty (2001), Paasche (2001), Mendoza (2002), and Scheneider and Tornell (2000)).

The stochastic RBC-SOE without credit constraints has the additional unappealing feature that it can lead to degenerate long-run distributions of equity and bonds in which domestic agents hold the smallest equity position $(\chi)$ and use bonds to engage in consumption smoothing and precautionary saving. The reason is that, without credit constraints and zero recurrent trading costs, risk-averse domestic agents demand a risk premium to hold equity (for standard equity-premium reasons) while risk-neutral foreign traders do not. ${ }^{5}$ Hence, domestic agents end up selling all the equity they can to foreign traders, although the process takes time because per-trade costs slow the speed at which foreign traders adjust their equity holdings.

To circumvent the problems of portfolio determination in the deterministic and stochastic RBC-SOE steady states, we calibrate the values of the financial frictions parameters $(a, \theta$ and $\kappa$ ) so that the allocations and prices obtained with the deterministic RBC-SOE steady state can be closely approximated as the deterministic steady state of an economy with negligible (but positive) recurrent trading costs and a margin constraint that is just slightly binding. This calibration scenario is labeled the "nearly frictionless economy" (NFE).

The deterministic steady state of the NFE has well-defined, unique solutions for bond and equity positions. In particular, foreign traders hold a stationary equity position at the price $q=q^{f} /(1+a \theta)$. Since this price is less than $q^{f}$, which is the price at which the return on domestic equity equals $R$, it follows that at this lower price $R^{q}>R$. Thus, foreign traders now require an equity premium to hold a stationary equity position. The ratio of the Lagrange multipliers of the domestic agent's margin constraint and budget constraint can then be found to be $\eta / \lambda=\left(R^{q}-R\right) /\left(R^{q}-R \kappa\right)$. In addition, since the margin constraint binds, bond holdings must satisfy $b=-\kappa \alpha q k$, and hence a unique stationary domestic equity position can be obtained from the steady-state consumption Euler equation. This is the value of $\alpha$ that solves the following expression:

$$
\left(1+\alpha k d+w n-\kappa q \alpha k(R-1)-\frac{n^{\delta}}{\delta}\right)^{\beta}=\frac{R}{1-(\eta / \lambda)}
$$

\footnotetext{
${ }^{5}$ With $\theta=0$ and no price guarantees, equation (15) implies that foreign traders attain a stationary equity position when the equity price equals the fundamentals price, and the latter implies a stationary asset return equal to $R$. Thus, at this steady state foreign traders hold equity at zero equity premium.
} 
Equation (26) illustrates the key role of the endogenous rate of time preference in supporting deterministic stationary equilibria with binding credit limits: it allows the rate of time preference to adjust so as to make the higher long-run consumption level, implied by the fact that the credit constraint prevents domestic agents from borrowing as they desire in the transition to steady state, to be consistent with the higher effective long-run real interest rate also implied by the credit constraint. The recurrent trading cost is also critical. With $\theta=0$, a stationary equity position for foreign traders requires a price equal to $q^{f}$ and a return on equity equal to $R$, but the latter implies that $\eta / \lambda=0$, so the borrowing constraint could not bind.

In the NFE steady state, the values of $a, \theta$ and $\kappa$ are set to support a deterministic steady state with a binding borrowing constraint that satisfies the following conditions: (1) the debt-GDP ratio is in line with Mexican data, (2) the allocations, factor payment rates and the equity price are nearly identical to those obtained for the frictionless RBC-SOE deterministic steady state, and (3) the elasticity of the foreign trader's demand curve is relatively high. The values of the financial frictions parameters are: $a=0.2, \theta=0.001$ and $\kappa=0.03$. With these parameter values, and the values set earlier for $\gamma, \delta, \beta$, and $R$, the NFE steady state yields values of $c, s, n, w, d, q$, and $R^{q}$ nearly identical to those of the RBC-SOE deterministic steady state, but the NFE also has unique portfolio allocations of $\alpha=0.931$ and $b=-4.825$ (which implies a debt-GDP ratio of about 0.62 ).

\subsection{Stochastic Simulation Framework}

The stochastic simulations are solved over a discrete state space with 78 evenly-spaced nodes in the equity grid and 120 evenly-spaced nodes in the bonds grid. The lower bound for domestic equity is set at $\chi=0.84$, so the equity grid spans the interval $[0.84,1]$. These equity bounds, together with the maximum equity price defined in (17) and the margin constraint, set the lower bound for bonds as $-\kappa q^{\max } k=-5.2$. This is the largest debt that the SOE could leverage by holding the largest possible equity position at the highest possible price. The upper bound of bonds is found by solving the model repeatedly starting with an upper bound that supports steady state savings with the equity position at its lowest, and then increasing the upper bound until the grid captures the support of the ergodic distribution of bonds. The resulting grid spans the interval $[-5.2,25.7]$. The segment of debt positions inside this interval is relatively small, reflecting the fact that, despite the frictions induced by asset trading costs, domestic agents still have a preference for riskless bonds as a vehicle to smooth consumption and build a buffer stock of savings.

A lower bound on domestic equity holdings of 84 percent seems much higher than the conventional short-selling limit set at 0 but it is consistent with the national aggregates targeted in the calibration. In Mexico, the average ratio of stock market capitalization to GDP in the period 1988-2000 was 27.6 percent. Since the calibration produced an estimate of the capitaloutput ratio of about 2.5, the total value of the shares of Mexican publicly traded firms constitutes just 11 percent of the capital stock. A large fraction of Mexico's capital stock is owned by non-publicly-traded firms and by owners of residential property, and thus does not have a liquid market in which to trade shares with foreign residents. In general, at the aggregate 
level of most emerging economies it is hard to argue that a large fraction of the physical capital stock has a liquid international market. Moreover, the result from the calibration exercise showing that bond positions become positive and unrealistically large when the domestic economy owns less than 90 percent of its capital also argues for a high value of $\chi$.

Productivity shocks are modeled as a two-point, symmetric Markov process that follows the "simple persistence" rule. The two points of the Markov chain and the transition probability matrix are set to produce moments of the limiting distribution of output that match the standard deviation and first-order autocorrelation of the quarterly cyclical component of Mexico's GDP reported in Mendoza (2004) -- 2.64 percent and 0.683 respectively. The model matches these moments using a Markov process of productivity shocks with a standard deviation $\left(\sigma_{\varepsilon}\right)$ of 1.79 percent and a first-order autocorrelation coefficient $\left(\rho_{\varepsilon}\right)$ of 0.683 . The simple persistence rule implies therefore that the two points of the Markov chain are symmetric and satisfy $-\varepsilon_{L}=\varepsilon_{H}=0.0179$ and these two states have the same long-run probability of $1 / 2$. The transition probability of remaining in either state is given by $1 / 2\left(1-\rho_{\varepsilon}\right)+\rho_{\varepsilon}=0.8415$ and the transition probability of shifting across states is $1 / 2\left(1-\rho_{\varepsilon}\right)=0.1585$.

\subsection{Baseline Results: Globalization Hazard and Sudden Stops without Price Guarantees}

The baseline results include four sets of simulation exercises. The first set is for the NFE

case. The second set is for the economy with binding margin requirements (BMR), for which the margin coefficient is set at $\kappa=0.005$. The third set introduces a simple price-guarantees policy that sets a single, non-state-contingent guaranteed price (NSCG) for all dates and states. The fourth set uses the same guaranteed price but as a state-contingent guarantee (SCG) that applies only in a subset of the state space.

The key result that emerges from the comparison between the NFE and BMR economies is that the financial frictions representing globalization hazard in the model cause Sudden Stops when the ratio of debt to the market value of equity is high and the equity market has enough liquidity (i.e., domestic agents are not at their short-selling limit). Since the comparison is similar to the one studied by Mendoza and Smith (2004), we keep the presentation short and refer the reader to their article for details.

Figures 2 shows the long run distributions of equity and bonds in the NFE and BMR economies. The effect of the margin constraint is clear in the bonds distribution. The distribution is biased to the left in the two economies but it shifts markedly to the right in the BMR case. The opposite occurs with the distribution of equity. The bias to the left in the distribution of equity reflects the incentive that risk-averse domestic agents have to sell equity to risk-neutral foreign traders. Binding margin constraints shift the equity distribution further to the left because of the equity fire sales triggered by margin calls.

The shifts in the distributions of equity and bonds also reflect the outcome of the precautionary saving effect. Domestic agents, aware of the imperfections of financial markets, have an incentive to build up a buffer stock of savings so as to minimize the risk of large declines in consumption, and in doing so they also lower the risk of facing states in which margin constraints bind in the long run (Figure 2 shows that the long run distribution of bonds 
of the BMR economy rules out states with very large debt positions). Still, Table 1 shows that the long-run probability of binding margin constraints is about 4 percent. Sudden Stops driven are therefore rare but non-zero probability events in the stochastic steady state (although many of the states in which margin constraints bind in the long run do not trigger Sudden Stops, as explained below). Note also that, since the buffer stock of savings is made of a portfolio of equity and bonds, margin constraints cause a portfolio reallocation of savings from equity into bonds. Table 1 shows that the long-run average of the bonds-output ratio increases from 18 percent in the NFE to 50 percent in the BMR economy.

Financial frictions have negligible effects on long-run business cycle moments (see Table 1). Hence, as in Mendoza and Smith (2004), we study Sudden Stops by examining the model's dynamics in the high-debt region of the state space in which the margin constraint binds (i.e., the "Sudden Stop region"). Figures 3-5 show the date-0 responses (or impact effects) of consumption, the current account-GDP ratio $(\mathrm{ca} / \mathrm{y})$ and equity prices to a negative, onestandard-deviation productivity shock for all possible date-0 $(\alpha, b)$ pairs in the Sudden Stop region, measured in percent of the long-run mean of each variable. The Sudden Stop region includes values of $b$ that are low enough (i.e., high enough debt) for the margin constraint to bind, and thus produce different impact effects in the BMR economy than in the NFE. This region includes the first 25 nodes of the bonds grid and all 72 points of the equity grid.

Figures 3-5 suggest that there are two key factors driving impact effects in the Sudden Stop region: (1) The leverage ratio, defined as the ratio of debt to the market value of equity, and (2) The liquidity of the equity market, defined as the difference between $\alpha$ and $\chi$. Sudden Stops with large reversals in $c$ and $c a / y$ occur when the leverage ratio is high (see Figures 3 and 4 ), but given high leverage the impact on asset prices is different depending on asset market liquidity. If the asset market is illiquid, the Sudden Stop can feature negligible asset price declines because domestic agents are close to $\chi$ and hence have little equity to sell (see Figure 5 ), but if there is some liquidity in the asset market, the Sudden Stop in $c$ and $c a / y$ is accompanied by a fall in $q$. In contrast, when the leverage ratio is sufficiently low and the asset market is sufficiently liquid, the drop in consumption and the current account reversal are small (nearly as small as in the NFE case) but the drop in asset prices is larger. In this case, domestic agents liquidate more equity and trigger larger asset price collapses, but they do so in order to swap their limited borrowing ability via bonds for equity sales so as to minimize the drop in consumption. This pattern of larger current account corrections coinciding with smaller asset price collapses fits the observations of some emerging markets crises. The current account reversal in the first quarter of 1995 in Mexico was 5.2 percent of GDP but the drop in real equity prices was nearly 29 percent. In contrast, in Korea the current account reversal in the first quarter of 1998 was twice as large but the asset price drop was just 10 percent.

Figure 6 illustrates Sudden Stop dynamics using the conditional forecasting functions of $c, q$ and $c a / y$. The first two are shown as percentages of their long-run averages in the NFE and the last is shown as the percentage points difference relative to the long-run average in the NFE. These forecasting functions represent non-linear impulse response functions to a negative, 
one-standard-deviation productivity shock conditional on initial positions of equity and bonds inside the Sudden Stop region. The Figures plot two sets of forecasting functions, one for a high leverage initial state, at which $\alpha=0.938$ and $b=-4.68$ (which imply a debt ratio of 60 percent of GDP and a leverage ratio of 3 percent of GDP), and one for a low leverage state with the same $\alpha$ but $b=-3.38$ (which imply a debt ratio of 43 percent of GDP and a leverage ratio of 2 percent of GDP). Since these initial states are distant from the corresponding long-run averages, the data in the Figures were adjusted to remove low-frequency transitional dynamics driven by the convergence of bonds and equity to their long-run means. Given that $c, q$ and $c a / y$ have nearly identical long-run averages in the four baseline experiments (except for the mean of $q$ in the NSCG economy, which is higher), the forecasting functions were detrended by taking differences relative to the NFE forecasting functions.

The impact effects in the initial date of the forecasting functions of the BMR economy differ sharply across the high and low leverage states, and those of the high leverage state deviate significantly from those of the NFE (or from zero in terms of Figure 6, since the data are plotted as differences relative to the NFE). In the high leverage state of the BMR economy, the negative shock triggers a Sudden Stop driven by the mechanisms described in Section 3: Domestic agents sell equity to meet margin calls and trigger a Fisherian deflation that reduces further their ability to borrow. The net result is that, on impact, a one-standard-deviation shock to productivity causes $c$ and $q$ to drop by 1.5 and 0.4 percent more than in the NFE respectively and $c a / y$ to rise by about 1 percentage point of GDP. In the low leverage state, domestic agents are better positioned to smooth consumption by substituting debt for equity to finance a current account deficit. As a result, the responses of $c$ and $c a / y$ in the BMR economy are nearly identical to those in the NFE, so their detrended forecasting functions hover around zero. This occurs even though the sales of equity still make $q$ fall by about the same amount as in the high leverage scenario. Notice also that the drop in asset prices is small relative to observed Sudden Stops, but very large relative to the standard deviation of asset prices in the NFE.

One caveat about the plots in Figure 6: The initial bond and equity positions used to generate them yield outcomes consistent with Sudden Stops, but the set of impact effects that the model predicts for all initial conditions inside the Sudden Stop region (including transitional dynamics components) are shown in Figures 3-5. As these Figures show, the Sudden Stop region includes scenarios with much larger consumption and current-account reversals than those shown in Figure 6, as well as scenarios in which there is little difference between the BMR and NFE because the asset market is sufficiently liquid to maintain a similar current account deficit by selling equity when the margin constraint binds. Precautionary saving implies, however, that all of the scenarios with very large reversals in consumption and the current account have zero probability in the long run. Notice also that, since the Sudden Stop region includes instances in which the margin constraint binds but fire sales of assets prevent a sharp current account reversal, the probability of binding margin constraints should not be interpreted as measuring the probability of Sudden Stops. 
Figure 6 suggests that Sudden Stops in the model are short-lived. The responses of the BMR economy converge to those of the NFE in about 4 quarters. Mendoza and Smith (2004) obtained Sudden Stops with more persistence using higher per-trade costs, which hamper the foreign traders' ability to adjust equity holdings. Mendoza (2004) also obtained more persistence by introducing costly capital accumulation in an environment in which margin constraints link the ability to borrow to the Tobin $\mathrm{Q}$ valuation of capital.

\subsection{Baseline Results: State-Contingent and Non-State-Contingent Price Guarantees}

The price guarantees are set as a percent above the fundamentals price in the low productivity state. ${ }^{6}$ This choice is based on a theoretical result that holds assuming stationary decision rules (i.e., $\alpha_{t+1}=\alpha_{t}, b_{t+1}=b_{t}$ ) and equilibrium equity prices in the high productivity state that exceed a time- and state-invariant guaranteed price. Under these assumptions, it is possible

to show that the present value of excess prices reduces to $G\left(\alpha, b, \varepsilon_{L}\right)=z\left(\tilde{q}-\frac{q^{f}\left(\varepsilon_{L}\right)}{1+a \theta}\right)$, where $z$ is a positive fraction that depends on $R, a, \theta$ and the transition probabilities of the shocks. Hence, under the stated assumptions, $\tilde{q}>\frac{q^{f}\left(\varepsilon_{L}\right)}{1+a \theta}$ is a necessary condition for price guarantees to be executed at least in some states of nature. Given the low values of $a$ and $\theta$, this condition suggests setting price guarantees above the fundamentals price in the low productivity state. The result does not apply strictly to the numerical solutions, however, because the decision rules are not generally stationary and equilibrium prices in the high productivity state can be lower than guaranteed prices.

The non-state-contingent price guarantee is set $1 / 2$ of a percentage point above the fundamentals price in the low productivity state (2.185). Hence, the guaranteed price is 2.196. This guarantee is offered in all states $(\alpha, b, \varepsilon)$ in the NSCG economy. In contrast, the economy with state-contingent price guarantees provides the same guaranteed price only for $(\alpha, b)$ pairs inside the Sudden Stop region.

Figure 7 shows the ergodic distributions of equity and bonds for the NSCG and SCG economies. Relative to the BMR case, the non-state-contingent guarantee shifts the distribution of equity (bonds) markedly to the left (right). The long-run average of the expected present value of excess prices (i.e., the long-run average of the $G(\cdot)$ function) is 0.01 , which is about $1 / 2$ of a percent above the mean equity price in the stochastic stationary state.

Comparing long-run moments across Panels I, II and III of Table 1, the main change caused by price guarantees is the reduction in the probability of hitting states with binding margin constraints. The price guarantee nearly rules out the possibility of hitting these states, compared to the 4-percent probability obtained in the BMR economy. The long-run moments of the model's endogenous variables vary slightly with the non-state-contingent guarantee. Asset-

\footnotetext{
${ }^{6}$ Setting a guaranteed price above the fundamentals price is not awkward because the model's fundamentals price does not correspond to the price of a frictionless environment. In the NFE case, asset markets are incomplete and risk-averse domestic agents trade equity with risk-neutral foreign traders. Hence, equilibrium prices reflect the equity premium and the distortions induced by incomplete markets, and thus differ from a fundamentals price that discounts dividends at the risk-free rate.
} 
price fluctuations display less variability, persistence and co-movement with output in the NSCG economy relative to the NFE and BMR cases. The mean equity price increases by 0.053 percent, slightly more than the percent difference between the guaranteed price and the fundamentals price of the low productivity state. The coefficient of variation of consumption falls by about $1 / 5$ of a percentage point and the variability of the current account and the trade balance increase slightly. Consumption also becomes less correlated with GDP.

The effects of the price guarantee on Sudden Stop dynamics are shown in Figure 6. Price guarantees are an effective policy for containing Sudden Stops. Comparing the NSCG and BMR economies in the high leverage state, the initial drop in consumption and current account reversal are smaller in the NSCG economy, and the drop in equity prices turns into an increase of about $1 / 4$ of a percentage point. In the low leverage state, the increase in equity prices in the NSCG economy is slightly larger than in the high leverage state, and we now obtain an increase in consumption and a widening of the current account deficit at date 0 . The price guarantee results in a price of equity at date 0 that is $2 / 3$ of a percentage point higher in the NSCG than in the BMR economy in both the high and low leverage states. Foreign traders execute the price guarantee in both states of the NSCG economy.

Figure 8 plots the levels of equity prices in the low productivity state of the NFE, BMR and NSCG economies for all equity and bond positions. The plots show that the non-statecontingent guarantee not only results in higher prices in the Sudden Stop region, but it actually results in higher prices in all states. In fact, the guarantee produces significantly higher asset prices in the NSCG economy than in either the NFE or BMR economies in states well outside the Sudden Stop region. This is a potentially important drawback of non-state-contingent price guarantees: they distort asset prices even when the economy is in states in which it is very far from being vulnerable to Sudden Stops.

One alternative to remedy the drawbacks of non-state-contingent price guarantees is to consider state-contingent guarantees. Figure 7 shows that the SCG economy yields a long-run distribution of equity (bonds) that is less skewed to the left (right) than in the NSCG economy. Table 1 shows that the changes in the long-run business cycle moments of the SCG economy relative to the NFE and BMR cases are qualitatively similar to those noted for the NSCG economy but the magnitude of the changes is smaller. The SCG economy still features near-zero percent probability of observing states of nature in which the margin constraint binds. Hence, the state-contingent guarantee is as effective as the non-state-contingent guarantee at eliminating the possibility of hitting states with binding margin requirements in the long run.

Figure 6 shows that, in both the high and low leverage states, the SCG economy features nearly-identical date- 0 responses in consumption and the current account as the NSCG economy and a slightly smaller recovery in asset prices. After date 0, the SCG economy converges faster to the dynamic paths of the NFE economy. Finally, a comparison of the middle and bottom plots of Figure 8 shows that the SCG economy yields higher asset prices mainly in the Sudden Stop region of the state space. Thus, the policy of state contingent guarantees induces smaller distortions on asset demand and asset prices than the non-state-contingent guarantees, 
particularly outside the Sudden Stop region, yet it has similar effects in terms of its ability to prevent Sudden Stops.

\subsection{Normative Implications of the Baseline Simulations}

We study next the normative implications of the baseline simulations by examining how domestic welfare and the value of foreign securities firms varies across the NFE, BMR, NSCG and SCG experiments. Welfare costs, $W(\alpha, b, \varepsilon)$, are measured by computing compensating variations in date- 0 consumption that equate expected lifetime utility in the BMR, NSCG and SCG economies with that of the NFE for any triple $(\alpha, b, \varepsilon)$ in the state space. Welfare effects are typically computed as compensating variations that apply to consumption at all dates, but in principle both measures are useful for converting ordinal units of utility into the cardinal units needed for quantitative welfare comparisons. The two measures yield identical welfare rankings for the four experiments, but the measure based on date-0 consumption highlights better the welfare costs of Sudden Stops and the potential benefits of price guarantees because large deviations from the consumption dynamics of the NFE occur only in Sudden Stop states (in which bond and equity positions are distant from their long-run averages).

The model belongs to the class of models in which capital markets are used to smooth consumption over the business cycle. Hence, since it is well-known that the welfare cost of "typical" consumption fluctuations is small in these models, the mean welfare costs of deviating from the $\operatorname{NFE}(\mathrm{E}[W(\alpha, b, \varepsilon)]$ computed with the ergodic distribution) should be small. As Table 2 shows, welfare comparisons based on date-0 consumption preserve this result. Agents in the BMR, NSCG and SCG economies incur average welfare losses relative to the NFE equivalent to cuts of less than 0.07 percent in $c_{0}$. This is also in line with Mendoza's (1991) results showing trivial welfare costs for giving up access to world capital markets in an RBC-SOE model.

The situation is very different when comparing welfare conditional on Sudden Stop states. Since the Bellman equation implies that lifetime utility as of date 0 can be expressed as $V(0)=u(0)+\exp (-v(0)) E_{0}[V(1)]$, Table 2 decomposes the total welfare cost into a short-run cost (i.e., the percent change in $c_{0}$ that equates $u(0)$ in the distorted economies with that of the $\mathrm{NFE}$ ) and a long-run cost (i.e., the percent change in $c_{0}$ that equates $\exp (-v(0)) E_{0}[V(1)]$ in the distorted economies with that of the NFE). The Table also lists the date-1 rate of time preference, $\exp (-v(0))$, to show that changes in the endogenous subjective discount factor play a negligible role in the welfare analysis.

In the high leverage Sudden Stop state, which is the one that in the BMR economy produces dynamics closer to those of observed Sudden Stops, the short-run welfare costs show that domestic agents are worse off in the BMR economy or in the economies with price guarantees than in the NFE. The welfare cost is 1.4 percent for the BMR economy and 0.9 and 1 percent for the NSCG and SCG economies respectively. This ranking reflects the fact that declines in date-0 consumption, and hence $u(0)$, are smallest in the NFE because it provides the best environment for consumption smoothing, followed by the economies in which price guarantees help contain the Sudden Stop that occurs in the BMR. 
The long-run costs are negative (i.e., domestic agents make welfare gains) because consumption after date-0 increases at least temporarily in the BMR, NSCG and SCG economies. In the high leverage case of the BMR economy, the binding credit constraint tilts the consumption profile by reducing consumption at date 0 and increasing it later, resulting in a long-run welfare gain of about 1 percent. Consumption tilting is also at work in the NSCG and SCG economies, but in addition the higher (distorted) asset prices lead to higher consumption relative to both the BMR and the NFE for three quarters beyond the initial date (see Figure 6). This expansion of consumption in the economies with price guarantees is driven in turn by larger current account deficits, which are financed by equity sales at higher prices. After the Sudden Stop at date 0, domestic agents set to rebalance their portfolios from equity into bonds gradually, but in economies with price guarantees the capital inflows from equity sales exceed the outflows from bond purchases in the early periods of transition thus producing larger external deficits. The result are long-run welfare gains in the high leverage NSCG and SCG economies (1.9 and 1.3 percent respectively) that are large enough to offset the short-run costs, so that domestic agents obtain total welfare gains of 1 percent in the NSCG and 0.3 percent in the SCG. These results show that the asset price changes induced by price guarantees represent non-trivial distortions relative to the NFE. Moreover, as we show below, the same distortions that increase domestic welfare in the high leverage Sudden Stop states of the NSCG and SCG economies reduce the value of the foreign traders' firms in those states.

At equilibrium, the foreign traders' net returns can be written as:

$$
\hat{\pi}(\alpha, b, \varepsilon) \equiv k\left[(1-\alpha) d(\varepsilon)-q(\alpha, b, \varepsilon)\left(\alpha-\hat{\alpha}^{\prime}(\alpha, b, \varepsilon)\right)-q(\alpha, b, \varepsilon)\left(\frac{a}{2}\right)\left(\alpha-\hat{\alpha}^{\prime}(\alpha, b, \varepsilon)+\theta\right)^{2}\right] .
$$

The terms inside the square brackets in the right-hand-side of this expression represent the foreign traders' dividend earnings, the net value of their trades at equilibrium, and the trading costs they incur. Notice that, since the budget constraint of the IFO holds, the lump sum taxes paid by foreign traders cancel with the value of the executed guarantees and hence the two do not appear in the above expression. Thus, price guarantees distort the traders' optimality condition with the moral hazard effect identified in (15) but do not have direct income effects.

As explained in Section 2, the payoff of foreign traders $D$ is the value of their firms: the expected present discounted value of the stream of net returns. In the recursive representation of the equilibrium, the present value of returns is a function $D(\alpha, b, \varepsilon)$, and hence we can compute long-run averages of net returns, $\mathrm{E}[D(\alpha, b, \varepsilon)]$, and values of $D(\alpha, b, \varepsilon)$ conditional on Sudden Sop states. Since the model has a well-defined stochastic steady state, the long-run mean of net returns is given by $E[D]=k E[\hat{\pi}] R(R-1)^{-1}$.

Table 2 shows that, relative to the NFE, $\mathrm{E}[D]$ and $E[\hat{\pi}]$ are 14.5 percent higher in the BMR economy and 52.6 and 42.5 percent higher in the NSCG and SCG economies respectively. Thus, from the perspective of the long-run average of the value of their firms, foreign traders are better off in the BMR economy and significantly better off in the economies with price guarantees than in the NFE. Table 2 also shows that this is the case mainly because of the increased average equity holdings of foreign traders in the BMR, NSCG and SCG economies, and the corresponding increase in their average dividend earnings. The contribution of changes 
in the value of trades to changes in $\mathrm{E}[D]$ and $E[\hat{\pi}]$ is zero by definition (since the unconditional means of $\alpha_{t}$ and $\alpha_{t+1}$ are identical) and the contribution of changes in trading costs is negligible. Foreign traders build up a larger equity position in the BMR economy as a result of the rebalancing of the portfolio of domestic agents from equity into bonds shown in Figure 2, and also because in some states foreign traders buy assets at crash prices (i.e., when domestic agents fire sale assets to meet margin calls). Foreign traders are much better off when price guarantees are in place because the price guarantees are equivalent to a guaranteed minimum return, which reduces sharply the downside risk of holding equity and results in even larger domestic portfolio reallocations from equity into bonds.

The result that the payoff of foreign traders is significantly higher on average in the long run when price guarantees are in place hides the fact that, when evaluated conditional on a Sudden Stop state, the payoff of foreign traders is lower in economies with price guarantees. Table 2 shows that the ranking of foreign traders' payoffs obtained by comparing $D(\alpha, b, \varepsilon)$ across Sudden Stop states with low or high leverage is the opposite from the one obtained by comparing $\mathrm{E}[D]$. Relative to the NFE, the present value of profits is nearly unchanged in the BMR economy and it falls in the high and low leverage states of the economies with price guarantees (by about 0.7 and 0.3 percent in the NSCG and SCG economies respectively). The latter occurs because in the NSCG and SCG economies the increase in the long-run average of net returns $(E[\hat{\pi}])$ is not sufficient to offset the short-run decline in returns $(\hat{\pi}(\alpha, b, \varepsilon))$ that occurs at date 0 when a Sudden Stop hits (see Table 2). In turn, this decline in net returns at date 0 is almost entirely driven by changes in the value of trades. The value of trades in the high (low) leverage state rises from 0.36 in the NFE to 3.93 (3.22) in the BMR economy and to about 3.95 (3.24) in the NSCG and SCG economies. In the BMR economy, the increase reflects the domestic agents' fire sales of equity to meet margin calls. The equity price falls, and when it falls foreign traders demand more equity and the value of their trades increases. In the economies with price guarantees, the moral hazard distortion exacerbates this effect by increasing the foreign traders' equity demand and producing equilibrium prices higher than in the BMR economy. In line with the increase in trading values, trading costs rise sharply from the NFE economy to the other economies, but their absolute amounts remain small. Dividend earnings do not change because date-0 equity holdings are the same in all four economies and the dividends of domestic firms are independent of financial frictions and price guarantees.

In principle, the present value of foreign traders' net returns conditional on a Sudden Stop state could be higher or lower with price guarantees than without depending on whether the short-run effect lowering date-0 net returns is weaker or stronger than the long-run effect increasing average net returns. The strength of these effects depends in turn on how much and how fast equilibrium equity positions and equity prices move, which depends on the parameters driving the demand for equity of domestic agents and foreign traders. According to Table 2, however, the substantial increases in the average payoff of foreign traders $(\mathrm{E}[D])$ in the NSCG and SCG economies exceed by large margins the small reductions in $D(\alpha, b, \varepsilon)$ to which foreign traders are exposed with very low probability in the long run. 
To analyze the distributional implications of price guarantees, consider the following "resource constraint" implied by the households' budget constraint and the definition of the traders' net returns:

$$
c=\varepsilon F(k, n)-\left[k \alpha^{*} d-b(R-1)\right]+\left[q k\left(\alpha^{\prime *}-\alpha^{*}\right)-\left(b^{\prime}-b\right)\right]
$$

The right-hand-side of this expression can be read as GNP (i.e., GDP plus net factor payments abroad in the form of dividends on equity and interest on bonds) plus the current account (i.e., changes in net foreign assets resulting from bond and equity trades), or GDP minus net exports.

As noted earlier, the long-run averages of consumption in the NFE, BMR, NSCG and SCG economies are nearly identical (see Table 1). On the other hand, Table 2 shows that the long-run average of the foreign traders' dividend earnings is higher in the latter three than in the NFE. Taking the long-run average of equation (28), it follows from these two observations that domestic agents are able to sustain similar long-run average consumption levels because their average savings remain nearly unchanged: The drop in dividend earnings on equity is nearly offset by increased interest income from bonds. Thus, these baseline results suggest that globalization hazard and price guarantees as modeled in this paper do not alter the long-run average shares of global income and wealth across the small open economy and the rest of the world. Foreign traders receive a larger share of domestic GDP but GNP is unaffected because domestic agents increase bond holdings and thus collect more interest income from abroad. The independence of GDP from financial frictions and price guarantees is a strong assumption that plays a key role in this result. The SOE assumption also plays a role because it allows the domestic portfolio swap of equity for bonds to occur without increasing the price of these bonds, which would lower the world interest rate.

Short-run distributional effects at a Sudden Stop state are different. GNP and GDP are unchanged across the four simulations, but there is a redistribution of world income via the current account. Relative to the NFE, foreign traders transfer income to domestic households in the BMR, NSCG and SCG economies, as the value of trades in the third term of the right-handside of (28) increases because domestic agents fire-sale equity to meet margin calls. But whether the domestic economy receives more or less income from the rest of the world as a whole depends on whether the fire sale of assets can prevent the current account reversal, which in turn depends on the leverage ratio and the liquidity of the asset market. Table 2 shows that $\hat{\pi}(\alpha, b, \varepsilon)$ falls at date 0 in the high and low leverage states, but Figure 6 shows that the reversal in $c a / y$ is larger in the former. Thus, the high leverage state features a redistribution of income from foreign traders to domestic agents via the equity market, but the larger current account reversal indicates that this redistribution is more than offset by the loss of access to the credit market, so that the domestic economy reduces the share of world output that it absorbs. In contrast, in the low leverage state the current account deficit remains close to the level of the NFE and hence the domestic economy maintains its share of world output. These results hold across the BMR, NSCG and SCG economies compared to the NFE but the effects are stronger in the economies with price guarantees. 
The above results show that, comparing long-run averages of the payoffs of domestic agents and foreign traders at the stochastic steady state, foreign traders are significantly better off in the economies with price guarantees than in the NFE or BMR economies while domestic agents are nearly indifferent. This suggests that price guarantees could be close to a win-win situation, but this result depends on controversial features of the model. In particular, domestic agents are nearly indifferent between the long-run outcomes of the four economies because of the trivial cost of consumption fluctuations in models of the class examined here, and foreign traders make large gains in the BMR, NSCG and SCG economies because their dividend earnings are unaffected by financial frictions. Moreover, from the perspective of Sudden Stop states, the moral hazard distortion of economies with price guarantees yields persistently higher asset prices which set in motion mechanisms that redistribute income from foreign traders to domestic agents by more than is needed if the aim were just to recover the outcome of the NFE, hence making domestic agents better off and foreign traders worse off. Still, foreign traders in the model suffer little because the sharp increase in E $[D]$ in the NSCG and SCG economies dwarfs the small, near-zero-probability reduction in $D(\alpha, b, \varepsilon)$ for Sudden Stop states.

\subsection{Sensitivity Analysis}

Table 3 reports the results of a sensitivity analysis that evaluates the robustness of the baseline results to the following parameter changes: Columns (II) and (III), larger and more persistent productivity shocks $\left(\sigma_{\varepsilon}=0.024\right.$ and $\left.\rho_{\varepsilon}=0.8\right)$, Column (IV), higher price guarantees ( 1 percent above $\left.q^{f}\left(\varepsilon_{L}\right)\right)$, Column $(\mathrm{V})$, higher recurrent trading costs $(\theta=0.01)$, and Column (VI), higher per-trade costs ( $a=2$, which implies an elasticity of the foreign traders' demand function of 0.5). Column (I) reproduces results for the corresponding baseline simulations. The Table shows panels with results for the BMR, NSCG and SCG economies for all six scenarios. In each case, three sets of results are listed: (a) Sudden Stop effects as measured by the detrended, date0 forecasting functions conditional on the high leverage state, (b) key moments of the ergodic distribution, and (c) changes in the payoffs of domestic agents and foreign traders, relative to the corresponding NFE simulation, for the high leverage Sudden Stop state and the long-run average of the stochastic steady state.

Consider first the BMR panel. Columns (I)-(VI) show that the results derived from the comparison of the baseline NFE and BMR economies are robust to the parameter changes considered here. Column (IV) has no data for the BMR panel because the BMR economy does not have price guarantees. The increases in $\sigma_{\varepsilon}$ and $\rho_{\varepsilon}$ resulted in small changes in Columns (II) and (III) relative to Column (I). The exceptions are the probability of binding margin constraints, which rises (falls) to $4.2(2.3)$ percent when $\rho_{\varepsilon}\left(\sigma_{\varepsilon}\right)$ increases, and the long-run average of the value of the foreign traders' firms, which falls to 12.2 and 4.4 percent in Columns (II) and (III) respectively. The changes in the probability of margin calls result from portfolio rebalancing effects. More persistent (variable) shocks increase (reduce) slightly the long-run average of domestic equity holdings, and have the opposite effects on the long-run average of bond holdings. As a result, the economy with more persistent (variable) shocks is more (less) likely to hit low bond positions (i.e., high debt positions) in which the margin constraint binds. 
In line with the findings of Mendoza and Smith (2004), Columns (V) and (VI) show that BMR economies with higher $\theta$ or higher $a$ display larger Sudden Stops, with the latter showing stronger effects. The long-run probability of margin calls is also sharply higher in these economies, reaching 16.7 percent with $\theta=0.01$ and 19.4 percent with $a=2$. The BMR economy with $a=2$ is the only scenario in Table 3 that can account for both large consumption and current account reversals and large drops in asset prices, as observed in actual Sudden Stops. This scenario also results in increased long-run variability in consumption and asset prices, and sharply higher domestic welfare costs. The cost in the high leverage Sudden Stop state is 4.1 percent and the long-run average cost is 0.1 percent (which is small but nearly ten times bigger than in the BMR baseline).

Comparing now Columns (I)-(VI) across the BMR, NSCG and SCG panels, we find that price guarantees always work to virtually eliminate the long-run probability of hitting states with binding margin constraints. On the other hand, the long-run probability of executing the guarantees is high in the NSCG economy, ranging between 29 and 34 percent in all scenarios except the one with higher $\sigma_{\varepsilon}$, in which it falls to 15 percent. In contrast, the probability of executing the guarantees in the SCG economy is below 1 percent in all the scenarios except those with $\theta=0.01$ and $a=2$, in which it reaches 6 and 3.2 percent respectively. Thus, statecontingent guarantees are as effective as non-state-contingent guarantees at reducing the longrun probability of margin calls, with the advantage that in the SCG economy the IFO would be trading much less frequently.

A comparison of Columns (I) and (IV) shows that rising the guaranteed price to a level 1 percent above $q^{f}\left(\varepsilon_{L}\right)$, twice as large than in the baseline simulations, the NSCG and SCG economies dampen the Sudden Stops of the BMR economy even more that in the baseline. With the higher price guarantee in Column (IV), the fall in $c$ is just $0.5(0.6)$ percent in the NSCG (SCG), compared to 0.8 (0.9) percent in the corresponding baseline simulations. Similarly, the reversal in $c a / y$ in the NSCG (SCG) is just $0.3(0.4)$ percentage points of GDP in Column (IV), compared to 0.6 (0.7) in Column (I). On the other hand, the economies with higher guarantees prop up asset prices in the Sudden Stop state even more than in Column (I), with price increases of $0.7(0.6)$ percent in the NSCG (SCG) economy. In line with the smaller consumption declines and larger price increases, the domestic welfare gain in the high leverage Sudden Stop state increases to 2.4 (0.9) percent in Column (IV) of the NSCG (SCG) economy compared to 1 (0.3) percent in the corresponding baseline simulations, while the long-run welfare losses remain nearly unchanged across Columns (I) and (IV). At the same time as the domestic welfare gains in the Sudden Stop state grow, the decline in the payoff of the foreign traders in the same state grows from 0.7 (0.3) percent in the NSCG (SCG) baseline to $1.4(0.9)$ percent in the NSCG (SCG) with higher guarantees. In contrast, the long-run average of the traders' payoff increases with the higher guarantees. Thus, the results regarding the effects of price guarantees obtained with the baseline simulations are qualitatively similar to those obtained with higher guarantees, but quantitatively the higher guarantees induce larger moral 
hazard distortions which result in weaker Sudden Stops but larger redistribution effects across foreign traders and domestic agents.

Column (VI) shows that, if the baseline level of price guarantees is applied to an economy with higher per-trade asset trading costs, the price guarantees still work to weaken the real effects of Sudden Stops relative to those in the BMR economy. However, with $a=2$ the guarantee set 0.5 percent above $q^{f}\left(\varepsilon_{L}\right)$ is insufficient to prevent marked reversals in $c$ and $c a / y$ and a sharp drop in $q$. Consequently, domestic agents suffer a substantial welfare loss of 1.5 (2.6) percent in the high leverage Sudden Stop state of the NSCG (SCG) economy, instead of the small gains obtained in the corresponding baseline simulations with $a=0.2$. Moreover, the long-run average of welfare costs increases about 5 (2) times in the NSCG (SCG) economy with $a=2$ relative to the same simulations with $a=0.2$. Interestingly, the payoff of the foreign traders in the high leverage Sudden Stop state is larger in the NSCG and SCG economies with $a=2$ than in their baseline counterparts with $a=0.2$. In fact, in the SCG economy with $a=2$ the value of the foreign traders' firm in the high leverage state is even higher than that in the corresponding NFE economy.

The above results show that, for a given guaranteed price, there can be a sufficiently high value of $a$ such that the distortions of globalization hazard and international moral hazard combine to yield outcomes in which domestic agents suffer large welfare losses at Sudden Stop states, but still these losses are smaller than in the BMR economy without guarantees. Moreover, for a given value of $a$, higher guarantees dampen Sudden Stops more and produce welfare gains at Sudden Stop states. These findings would suggest that the IFO should set higher price guarantees the higher are trading costs. The results also show, however, that economies with higher $a$ face higher long-run averages of welfare costs with price guarantees than without them (the cost is $1 / 3$ of a percent in the NSCG panel of Column (VI), compared to $1 / 10$ of a percent in the corresponding BMR). In addition, economies with higher guarantees and the baseline value of $a$ also yield larger long-run welfare losses with price guarantees (see Column IV). Thus, if per-trade trading costs are high, increasing price guarantees makes domestic agents better off at Sudden Stop states by weakening more the real effects of globalization hazard, but the stronger adverse effects of international moral hazard make domestic agents worse off on average in the long run.

The findings of the sensitivity analysis suggest that the size of per-trade costs plays a crucial role in determining the effectiveness of price guarantees and the direction of the tradeoff between globalization hazard and moral hazard. Mendoza and Smith (2004) showed that this parameter is also crucial for the model's ability to account for asset price collapses of the magnitude observed in Sudden Stops, and documented empirical evidence of trading costs in actual asset markets roughly in line with the model's predictions. Using the same values of $a$ and $\theta$ as in the baseline calibration of this paper, they found that trading costs in the BMR economy peak inside the Sudden Stop region and reach a maximum of 6.4 percent of equity returns. The empirical literature they surveyed estimates trading costs ranging from 4.8 to 8.8 percent across industrial countries and emerging markets. Nevertheless, the crucial feature is not 
the magnitude of $a$ itself but the elasticity of world demand for the SOE's equity, which can be influenced by factors other than standard measures of trading costs. The findings of this paper suggest that, if this elasticity is high, it is relatively easy to design a system of state-contingent price guarantees that reduces the probability of margin calls, undoes the Sudden Stop effects of globalization hazard, and makes domestic agents better off at Sudden Stop states with negligible effects on foreign traders returns in those states, and with trivial implications on the long-run welfare of domestic agents. On the other hand, as the elasticity falls, price guarantees still weaken Sudden Stops but the tradeoff between globalization hazard and moral hazard can have negative consequences for domestic welfare.

\section{Conclusions}

The equilibrium asset pricing theory presented in this paper suggests that, in the presence of globalization hazard characterized by world capital market frictions, providing exante price guarantees on the emerging markets asset class can be an effective means to contain Sudden Stops. The same theory predicts, however, that these guarantees introduce a distortion that induces an international moral hazard effect propping up the foreign investors' demand for emerging markets assets. Hence, ex-ante price guarantees create a tradeoff between the benefits of undoing globalization hazard and the costs of creating international moral hazard.

The paper borrows from Mendoza and Smith (2004) the setup of a dynamic, stochastic general equilibrium model of asset prices in which collateral constraints and asset trading costs are the sources of globalization hazard causing Sudden Stops. Collateral constraints are modeled as margin constraints that limit the ability of domestic agents to leverage foreign debt on equity holdings. Asset trading costs are incurred by foreign traders and take the form of per-trade costs and recurrent costs paid regardless of trading activity. In this environment, typical realizations of the underlying shocks that drive business cycles trigger margin calls if they hit the economy when its stock of foreign debt is sufficiently large relative to the market value of domestic equity. Margin calls lead to a fire sale of equity by domestic agents and a Fisherian debtdeflation of asset prices. If domestic asset markets are relatively illiquid, the result is a Sudden Stop with a collapse in consumption, a current account reversal and a fall in asset prices.

This paper introduced into the Mendoza-Smith model an IFO that offers foreign traders ex-ante guarantees on the prices of an emerging economy's assets by setting up a facility credibly committed to buy these assets from them at pre-announced minimum prices. If the guarantees are executed, their cost is financed with a lump sum tax on foreign traders' returns. The international moral hazard distortion that these guarantees create increases the foreign traders' demand for the emerging economy's assets by an amount proportional to the traders' conditional expected present value of the excess of guaranteed prices over market prices.

The quantitative analysis based on a calibration to Mexican data showed that a guaranteed price set $1 / 2$ to 1 percent above the model's "fundamentals" price in a low productivity state reduces significantly the Sudden Stop effects of globalization hazard. This guarantee also eliminates the long-run probability of margin calls in the stochastic steady state. If the guarantee is non-state-contingent, however, the IFO trades often (with a long-run 
probability of executing the guarantee of about $1 / 3$ ), and the model predicts persistent overvaluation of asset prices above the prices obtained without globalization hazard. The IFO trades much less often, with a long run probability below $1 / 100$, if the same guaranteed price is offered as a state-contingent guarantee that applies only at high levels of external debt. These state-contingent guarantees are no less effective at containing Sudden Stops and they do not result in persistent asset overvaluation.

The effectiveness of price guarantees to prevent Sudden Stops and increase social welfare hinges on the relative magnitude of globalization hazard and international moral hazard. In the model of this paper, the size of per-trade costs that determine the price elasticity of world demand for the emerging economy's assets is a key determinant of both: The Fisherian debtdeflation depends on how much prices have to fall for foreign traders' to accommodate the fire sales of domestic assets. The moral hazard distortion increases foreign demand for domestic assets by an amount equal to the product of the expected present value of excess prices multiplied by the price elasticity. With per-trade costs that yield an elasticity of 5 , the guaranteed price of $1 / 2$ to 1 percent above the low-productivity fundamentals price reduces Sudden Stop effects on consumption, asset prices and the current account. This results in domestic welfare gains when the economy is at a Sudden Stop state, with negligible changes in long-run welfare. At the same time, the value of foreign traders' firms in a Sudden Stop state falls slightly but the long-run average rises sharply. Hence, in this case the benefits of price guarantees to contain globalization hazard outweigh the costs of international moral hazard.

These results are reverted when per-trade costs yield an elasticity of world demand for domestic equity of $1 / 2$. In this case, globalization hazard causes larger Sudden Stops and higher price guarantees are needed to contain them. However, even with the guarantees at $1 / 2$ to 1 percent above the low-productivity fundamentals price, which cannot prevent reversals in consumption and the current account, the moral hazard distortion is magnified significantly. Welfare gains for the emerging economy at Sudden Stop states are smaller, and the economy suffers non-trivial welfare losses in the stochastic steady state. In this case, price guarantees yield a short-term improvement in macroeconomic indicators and welfare because they weaken globalization hazard, but international moral hazard outweighs this benefit and causes a longrun welfare loss. This outcome can be altered increasing guaranteed prices (so that Sudden Stop effects are contained) and adjusting the state-contingent structure of the policy (so that the moral hazard distortion is weakened) at the same time.

The challenge to the IFO is to design ex-ante price guarantees that yield outcomes that clearly dominate those obtained when there is no policy in place to contain Sudden Stops. The findings of our quantitative analysis, particularly those highlighting the advantages of statecontingent guarantees, illustrate the complexity of this task. But the task is also difficult because designing an effective system of price guarantees requires a "useful" model of asset prices (i.e., a model that explains the quantitative features of Sudden Stops and that can be used to quantify the effects of the guarantees taking into account how they affect the optimal plans of forward-looking agents). With trading costs in the neighborhood of those suggested by 
the empirical literature, the Mendoza-Smith model produces large reversals in consumption and the current account, and collapses in asset prices. On the other hand, the model is by construction unable to account for the Sudden Stops' large output and investment collapses. Moreover, the challenge to develop a "useful" model applies to ex-ante as well as ex-post price guarantees. The ex-post systems of the Lerrick-Meltzer and IMF proposals assume that "useful" models are at hand to establish sustainable levels of external debt, as well as "normal" and crash prices of emerging economies' assets. This paper makes some progress towards developing a "useful" model for designing a system of ex-ante price guarantees to prevent Sudden Stops, but clearly there is a lot left for further research. 
References

Arellano, Cristina and Enrique G. Mendoza (2003), "Credit Frictions and 'Sudden Stops' in Small Open Economies: An Equilibrium Business Cycle Framework for Emerging Markets Crises," in Dynamic Macroeconomic Analysis" S. Altug, J. Chadha and C. Nolan eds., Cambridge Univ. Press, Cambridge.

Caballero, Ricardo J. and Arvind Krishnamurthy (2001), "International and Domestic Collateral Constraints in a Model of Emerging Market Crises," Journal of Monetary Economics, v.48, 513548.

Calvo, Guillermo A. (2002), "Globalization Hazard and Delayed Reform in Emerging Markets," Economia, Spring, v. 2, no. 2. (1998), "Capital Flows and Capital-Market Crises: The Simple Economics of Sudden Stops," Journal of Applied Economics, v.1, pp 35-54.

and Enrique G. Mendoza (2000a), "Capital-Market Crises and Economics Collapse in Emerging Markets: An Informational-Frictions Approach," American Economic Review: Papers E Proceedings, May. and Enrique G. Mendoza (2000b), "Rational Contagion and the Globalization of Securities Markets," Journal of International Economics, v.51.

Epstein Larry G. (1983), "Stationary Cardinal Utility and Optimal Growth under Uncertainty," Journal of Economic Theory, 31, 133-152.

Frankel, Jeffrey and Sebastian Edwards (2002), Preventing Currency Crises in Emerging Markets. An NBER Conference Report. Chicago: University of Chicago Press.

Fisher, Irving (1933), "The Debt-Deflation Theory of Great Depressions," Econometrica 1, 33757.

Greenwood, Jeremy, Zvi Hercowitz and Gregory W. Huffman (1988), "Investment, Capacity Utilization and the Real Business Cycle," American Economic Review, June.

International Monetary Fund (1999), International Capital Markets, September, International Monetary Fund, Washington:DC.

Izquierdo, Alejandro (2000) "Credit Constraints, and the Asymmetric Behavior of Asset Prices and Output under External Shocks," mimeo, The World Bank. June.

Kiyotaki, Nobuhiro and John Moore (1997), "Credit Cycles," Journal of Political Economy, v.105, 211-248.

Krugman, Paul (2000) "Fire-Sale FDI," in Capital Flows and the Emerging Economies, Sebastian Edwards ed. Chicago: University of Chicago Press.

Lerrick, Adam, and Allan H. Meltzer (2003), "Blueprint for an International Lender of Last Resort," Journal of Monetary Economics, v.50, 289-3003.. 
Ljungqvist, Lars (2000) "Government Guarantees on Assets and Volatility," mimeo, Stockholm School of Economics.

Mendoza, Enrique G. (1991), "Capital Controls and the Dynamic Gains from Trade in a Business Cycle Model of a Small Open Economy," IMF Staff Papers, September.

(2002), "Credit, Prices, and Crashes: Business Cycles with a Sudden Stop." In Preventing Currency Crises in Emerging Markets, Frankel, Jeffrey and Sebastian Edwards eds. Chicago: University of Chicago Press.

and Katherine A. Smith (2004), "Quantitative Implications of a Debt-Deflation Theory of Sudden Stops and Asset Prices," NBER Working Paper No. 10940, National Bureau of Economic Research.

(2004), "'Sudden Stops' in an Equilibrium Business Cycle Model with Credit Constraints: A Fisherian Deflation of Tobin's q," mimeo, Dept. of Economics, Univ. of Maryland.

Paasche, Bernhard (2001), "Credit Constraints and International Financial Crises," Journal of Monetary Economics, v.28, 623-650.

Schneider, Martin and Aron Tornell (1999), "Lending Booms, Asset Price Inflation and Soft Landings," mimeo, Department of Economics, University of California at Los Angeles.

Valderrama, Diego (2003), "The Impact of Financial Frictions on a Small Open Economy: When Current Account Borrowing Hits a Limit," mimeo, Research Department, Federal Reserve Bank of San Francisco. 
Table 1. Long Run Business Cycle Moments

\begin{tabular}{|c|c|c|c|c|c|}
\hline Variable & mean & $\begin{array}{l}\text { std. dev. } \\
\text { (in \%) }\end{array}$ & $\begin{array}{l}\text { std. dev. } \\
\text { relative to } \\
\text { GDP }\end{array}$ & $\begin{array}{l}\text { correlation } \\
\text { w/ GDP }\end{array}$ & $\begin{array}{l}\text { first-order } \\
\text { auto- } \\
\text { correlation }\end{array}$ \\
\hline \multicolumn{6}{|c|}{ I. NFE } \\
\hline GDP & 7.833 & 2.644 & 1.000 & 1.000 & 0.683 \\
\hline consumption & 5.366 & 2.185 & 0.826 & 0.853 & 0.770 \\
\hline current account-GDP ratio & 0.000 & 1.347 & 0.509 & 0.979 & 0.660 \\
\hline trade balance-GDP ratio & 0.315 & 0.948 & 0.358 & 0.564 & 0.811 \\
\hline equity price & 2.187 & 0.121 & 0.046 & 0.961 & 0.606 \\
\hline foreign debt-GDP ratio & 0.177 & 56.694 & 21.442 & -0.076 & 0.997 \\
\hline debt-equity ratio & 0.010 & 2.888 & 1.092 & 0.000 & 0.001 \\
\hline \multicolumn{6}{|c|}{ II. BMR Economy (probability of binding margin constraints $=3.973 \%$ ) } \\
\hline GDP & 7.833 & 2.644 & 1.000 & 1.000 & 0.683 \\
\hline consumption & 5.365 & 2.186 & 0.827 & 0.856 & 0.771 \\
\hline current account-GDP ratio & 0.000 & 1.324 & 0.501 & 0.982 & 0.664 \\
\hline trade balance-GDP ratio & 0.315 & 0.940 & 0.355 & 0.565 & 0.823 \\
\hline equity price & 2.187 & 0.121 & 0.046 & 0.962 & 0.609 \\
\hline foreign debt-GDP ratio & 0.499 & 37.964 & 14.358 & -0.118 & 0.994 \\
\hline debt-equity ratio & 0.026 & 2.007 & 0.759 & 0.000 & 0.001 \\
\hline \multicolumn{6}{|c|}{ III. NSCG Economy (probability of binding margin constraints $=0.001 \%$ ) } \\
\hline GDP & 7.833 & 2.644 & 1.000 & 1.000 & 0.683 \\
\hline consumption & 5.362 & 2.052 & 0.776 & 0.790 & 0.724 \\
\hline current account-GDP ratio & 0.000 & 1.487 & 0.562 & 0.968 & 0.660 \\
\hline trade balance-GDP ratio & 0.315 & 1.111 & 0.420 & 0.631 & 0.750 \\
\hline equity price & 2.198 & 0.099 & 0.037 & 0.891 & 0.384 \\
\hline foreign debt-GDP ratio & 1.336 & 41.053 & 15.526 & 0.001 & 0.992 \\
\hline debt-equity ratio & 0.071 & 2.186 & 0.827 & 0.000 & 0.006 \\
\hline \multicolumn{6}{|c|}{ IV. SCG Economy (probability of binding margin constraints $=0.001 \%$ ) } \\
\hline GDP & 7.833 & 2.644 & 1.000 & 1.000 & 0.683 \\
\hline consumption & 5.364 & 2.121 & 0.802 & 0.834 & 0.765 \\
\hline current account-GDP ratio & 0.000 & 1.380 & 0.522 & 0.974 & 0.660 \\
\hline trade balance-GDP ratio & 0.315 & 1.000 & 0.378 & 0.599 & 0.788 \\
\hline equity price & 2.188 & 0.121 & 0.046 & 0.903 & 0.630 \\
\hline foreign debt-GDP ratio & 1.114 & 34.141 & 12.912 & -0.067 & 0.991 \\
\hline debt-equity ratio & 0.059 & 1.810 & 0.685 & 0.000 & 0.004 \\
\hline
\end{tabular}

Note: NFE is nearly frictionless economy, BMR is economy with binding margin requirements, NSCG is economy with binding margin requirements and non-state-contingent guarantees, and SCG is economy with binding margin requirements and state-contingent guarantees. 
Table 2. Payoffs of Domestic Agents and Foreign Traders in Baseline Simulations

\begin{tabular}{lcccc}
\hline \hline & NFE & BMR & NSCG & SCG \\
\hline & I. Long-run averages & & \\
$\begin{array}{l}\text { Domestic Agents } \\
\text { Welfare cost 1/ }\end{array}$ & & 0.017 & 0.062 & 0.057 \\
$\begin{array}{l}\text { Foreign Traders } \\
\text { Present value of traders' returns }\end{array}$ & 17.920 & 20.519 & 27.350 & 25.529 \\
$\quad$ percent change w.r.t. NFE & & 14.499 & 52.621 & 42.460 \\
Returns & 0.280 & 0.321 & 0.427 & 0.399 \\
(a) dividend earnings & 0.280 & 0.320 & 0.427 & 0.399 \\
(b) trading costs & $1.1 \mathrm{E}-05$ & $2.3 \mathrm{E}-05$ & $8.8 \mathrm{E}-05$ & $1.6 \mathrm{E}-04$
\end{tabular}

\section{High leverage Sudden Stop State}

Domestic Agents

Welfare cost $1 /$

(a) short-run cost 2/
(b) long-run cost $3 /$

0.367

$-1.036$

$-0.317$

1.376

0.862

0.978

Date-1 rate of time preference

$-1.010$

$-1.899$

$-1.295$

Foreign Traders

Present value of traders' returns

1.58

1.56

1.57

1.57

percent change w.r.t. NFE

$\begin{array}{cccc}10.931 & 10.940 & 10.858 & 10.901 \\ & 0.082 & -0.670 & -0.276 \\ -0.192 & -3.770 & -3.796 & -3.791 \\ 0.166 & 0.166 & 0.166 & 0.166 \\ 0.359 & 3.927 & 3.953 & 3.948 \\ 1.6 \mathrm{E}-04 & 9.8 \mathrm{E}-03 & 9.8 \mathrm{E}-03 & 9.8 \mathrm{E}-03\end{array}$

Returns at date 0

(a) dividend earnings

$1.6 \mathrm{E}-04$

9.8E-03

9.8E-03

$9.8 \mathrm{E}-03$

III. Low leverage Sudden Stop State

Domestic Agents

Welfare cost $1 /$

(a) short-run cost $2 /$

0.215

$-1.194$

$-0.393$

(b) long-run cost $3 /$

0.055

$-0.356$

$-0.293$

Date-1 rate of time preference

0.160

$-0.838$

$-0.100$

Foreign Traders

Present value of traders' returns

1.59

1.59

1.59

1.59

percent change w.r.t. NFE

10.931

10.937

10.854

10.901

Returns at date 0

(a) dividend earnings

$-0.192$

0.055

$-0.707$

$-0.272$

(b) value of trades

0.166

$-3.056$

$-3.077$

$-3.074$

(c) trading costs

0.359

0.166

0.166

0.166

3.215

3.237

3.234

$1 /$ Compensating variation in date-0 consumption that equates expected lifetime utility obtained in the BMR, NSCG and SCG economies with that of the NFE.

$2 /$ Compensating variation in date-0 consumption that equates date-0 period utility obtained in the BMR, NSCG and SCG economies with that of the NFE.

3/ Difference of total welfare cost minus short-run cost. 
Table 3. Sensitivity Analysis

\begin{tabular}{|c|c|c|c|c|c|c|}
\hline & \multirow{3}{*}{$\frac{\text { Baseline }}{(I)}$} & \multicolumn{2}{|c|}{ Productivity Shocks } & \multirow{3}{*}{$\begin{array}{l}\frac{\text { Guarantees }}{(\mathrm{IV})} \\
1 \% \text { above } q^{f}\end{array}$} & \multicolumn{2}{|c|}{ Trading Costs } \\
\hline & & (II) & (III) & & $(\mathrm{V})$ & $(\mathrm{VI})$ \\
\hline & & $\rho=0.8$ & $\sigma_{\varepsilon}=2.4 \%$ & & $\theta=0.01$ & $a=2$ \\
\hline \multicolumn{7}{|c|}{ I. BMR Economy } \\
\hline \multicolumn{7}{|c|}{ Initial responses in high leverage state } \\
\hline consumption & -1.335 & -1.380 & -1.404 & n.a. & -1.453 & -3.059 \\
\hline current account-GDP ratio & 0.939 & 0.972 & 0.997 & n.a. & 1.023 & 2.157 \\
\hline equity price & -0.413 & -0.413 & -0.413 & n.a. & -0.412 & -4.324 \\
\hline traders' returns & -4.529 & -4.526 & -4.526 & n.a. & -4.522 & -4.866 \\
\hline \multicolumn{7}{|l|}{ Moments of the ergodic distribution } \\
\hline Prob. of binding mar. cons. (\%) & 3.973 & 4.200 & 2.331 & n.a. & 16.740 & 19.444 \\
\hline Averages & & & & n.a. & & \\
\hline consumption & 5.365 & 5.369 & 5.366 & & 5.369 & 5.378 \\
\hline equity price & 2.187 & 2.187 & 2.187 & n.a. & 2.183 & 2.183 \\
\hline equity holdings & 0.883 & 0.885 & 0.861 & n.a. & 0.906 & 0.907 \\
\hline Standard deviations (\%) & & & & n.a. & & \\
\hline consumption & 2.186 & 2.382 & 2.721 & n.a. & 2.169 & 2.454 \\
\hline current account-GDP ratio & 1.324 & 1.325 & 2.020 & & 1.432 & 1.428 \\
\hline equity price & 0.121 & 0.184 & 0.100 & n.a. & 0.114 & 0.463 \\
\hline Domestic welfare loss $1 /$ & & & & n.a. & & \\
\hline high leverage state & 0.367 & 0.361 & 0.389 & n.a. & 0.490 & 4.074 \\
\hline long-run average & 0.017 & 0.013 & 0.012 & n.a. & 0.099 & 0.110 \\
\hline \multicolumn{7}{|l|}{ Change in PDV of traders' returns $1 /$} \\
\hline high leverage state & 0.083 & 0.082 & 0.095 & n.a. & 3.448 & 0.924 \\
\hline long-run average & 14.502 & 12.163 & 4.354 & n.a. & 34.519 & 27.531 \\
\hline \multicolumn{7}{|c|}{ II. NSCG Economy } \\
\hline \multicolumn{7}{|c|}{ Initial responses in high leverage state } \\
\hline consumption & -0.840 & -0.875 & -0.901 & -0.503 & -0.885 & -2.205 \\
\hline current account-GDP ratio & 0.591 & 0.616 & 0.640 & 0.354 & 0.623 & 1.554 \\
\hline equity price & 0.259 & 0.274 & 0.214 & 0.718 & 0.362 & -3.256 \\
\hline traders' returns & -4.562 & -4.560 & -4.561 & -4.586 & -4.561 & -4.926 \\
\hline \multicolumn{7}{|l|}{ Moments of the ergodic distribution } \\
\hline Prob. of binding mar. cons. (\%) & 0.001 & 0.017 & 0.024 & 0.002 & 0.002 & 0.000 \\
\hline Prob. of executing guarantee (\%) & 34.290 & 32.892 & 15.434 & 29.650 & 34.068 & 28.925 \\
\hline \multicolumn{7}{|l|}{ Averages } \\
\hline consumption & 5.362 & 5.365 & 5.360 & 5.361 & 5.362 & 5.362 \\
\hline equity price & 2.198 & 2.199 & 2.198 & 2.208 & 2.198 & 2.206 \\
\hline equity holdings & 0.844 & 0.844 & 0.844 & 0.842 & 0.844 & 0.842 \\
\hline expected PDV of excess prices & 0.012 & 0.013 & 0.011 & 0.022 & 0.015 & 0.023 \\
\hline \multicolumn{7}{|l|}{ Standard deviations (\%) } \\
\hline consumption & 2.052 & 2.269 & 2.615 & 2.014 & 2.047 & 2.191 \\
\hline current account-GDP ratio & 1.487 & 1.473 & 2.035 & 1.567 & 1.490 & 1.584 \\
\hline equity price & 0.099 & 0.149 & 0.104 & 0.091 & 0.100 & 0.429 \\
\hline expected PDV of excess prices & 2.083 & 3.913 & 4.235 & 1.375 & 1.368 & 1.466 \\
\hline
\end{tabular}


Table 3. Sensitivity Analysis (Continued)

\begin{tabular}{|c|c|c|c|c|c|c|}
\hline & \multirow{3}{*}{$\frac{\text { Baseline }}{\text { (I) }}$} & \multicolumn{2}{|c|}{ Productivity Shocks } & \multirow{3}{*}{$\begin{array}{l}\frac{\text { Guarantees }}{(\mathrm{IV})} \\
1 \% \text { above } q^{f}\end{array}$} & \multicolumn{2}{|c|}{ Trading Costs } \\
\hline & & (II) & (III) & & $(\mathrm{V})$ & $(\mathrm{VI})$ \\
\hline & & $\rho=0.8$ & $\sigma_{\varepsilon}=2.4 \%$ & & $\theta=0.01$ & $a=2$ \\
\hline \multicolumn{7}{|l|}{ Domestic welfare loss $1 /$} \\
\hline high leverage state & -1.036 & -1.137 & -1.033 & -2.359 & -1.025 & 1.506 \\
\hline long-run average & 0.062 & 0.063 & 0.132 & 0.086 & 0.286 & 0.332 \\
\hline \multicolumn{7}{|l|}{ Change in PDV of traders' returns $1 /$} \\
\hline high leverage state & -0.670 & -0.732 & -0.660 & -1.372 & 2.501 & -0.459 \\
\hline long-run average & 52.621 & 51.867 & 17.567 & 54.696 & 122.862 & 116.646 \\
\hline \multicolumn{7}{|c|}{ III. SCG Economy } \\
\hline \multicolumn{7}{|c|}{ Initial responses in high leverage state } \\
\hline consumption & -0.952 & -0.878 & -0.988 & -0.626 & -0.920 & -2.182 \\
\hline current account-GDP ratio & 0.670 & 0.618 & 0.702 & 0.440 & 0.648 & 1.538 \\
\hline equity price & 0.107 & 0.270 & 0.105 & 0.550 & 0.313 & -3.227 \\
\hline traders' returns & -4.555 & -4.560 & -4.555 & -4.586 & -4.558 & -4.928 \\
\hline \multicolumn{7}{|l|}{ Moments of the ergodic distribution } \\
\hline Prob. of binding mar. cons. (\%) & 0.001 & 0.014 & 0.042 & 0.009 & 0.013 & 0.000 \\
\hline Prob. of executing guarantee (\%) & 0.035 & 0.261 & 0.391 & 0.502 & 6.063 & 3.245 \\
\hline \multicolumn{7}{|l|}{ Averages } \\
\hline consumption & 5.364 & 5.369 & 5.363 & 5.363 & 5.358 & 5.355 \\
\hline equity price & 2.188 & 2.188 & 2.189 & 2.190 & 2.190 & 2.191 \\
\hline equity holdings & 0.855 & 0.855 & 0.855 & 0.850 & 0.879 & 0.874 \\
\hline expected PDV of excess prices & 0.002 & 0.002 & 0.011 & 0.003 & 0.007 & 0.009 \\
\hline \multicolumn{7}{|l|}{ Standard deviations (\%) } \\
\hline consumption & 2.121 & 2.317 & 2.709 & 2.095 & 2.061 & 2.298 \\
\hline current account-GDP ratio & 1.380 & 1.369 & 2.028 & 1.420 & 1.466 & 1.536 \\
\hline equity price & 0.121 & 0.187 & 0.120 & 0.137 & 0.154 & 0.469 \\
\hline expected PDV of excess prices & 42.186 & 62.894 & 4.235 & 52.202 & 37.543 & 51.111 \\
\hline \multicolumn{7}{|l|}{ Domestic welfare loss1/ } \\
\hline high leverage state & -0.317 & -0.481 & -0.297 & -0.869 & -0.385 & 2.596 \\
\hline long-run average & 0.057 & 0.053 & 0.033 & 0.054 & 0.086 & 0.121 \\
\hline \multicolumn{7}{|l|}{ Change in PDV of traders' returns $1 /$} \\
\hline high leverage state & -0.276 & -0.359 & -0.246 & -0.567 & 2.985 & 0.167 \\
\hline long-run average & 42.460 & 41.196 & 9.446 & 47.217 & 72.049 & 73.680 \\
\hline
\end{tabular}

Note: The guaranteed price is 0.5 percent ( 1 percent for column (IV)) above the fundamentals price in the low productivity state of the baseline simulation. Welfare costs are compensating variations in initial consumption that equalize lifetime utility in each simulation with that of the corresponding NFE. Initial responses are in percent of the corresponding NFE and detrended as described in the text (except the response for traders' returns which is in percent of the capital stock and the response for the current account-output ratio which is the difference in percentage points relative to the corresponding NFE).

1/Percentage change relative to NFE 
Figure 2. Ergodic Distributions of Domestic Equity and Bond Holdings in NFE and BMR Economies

Domestic Equity
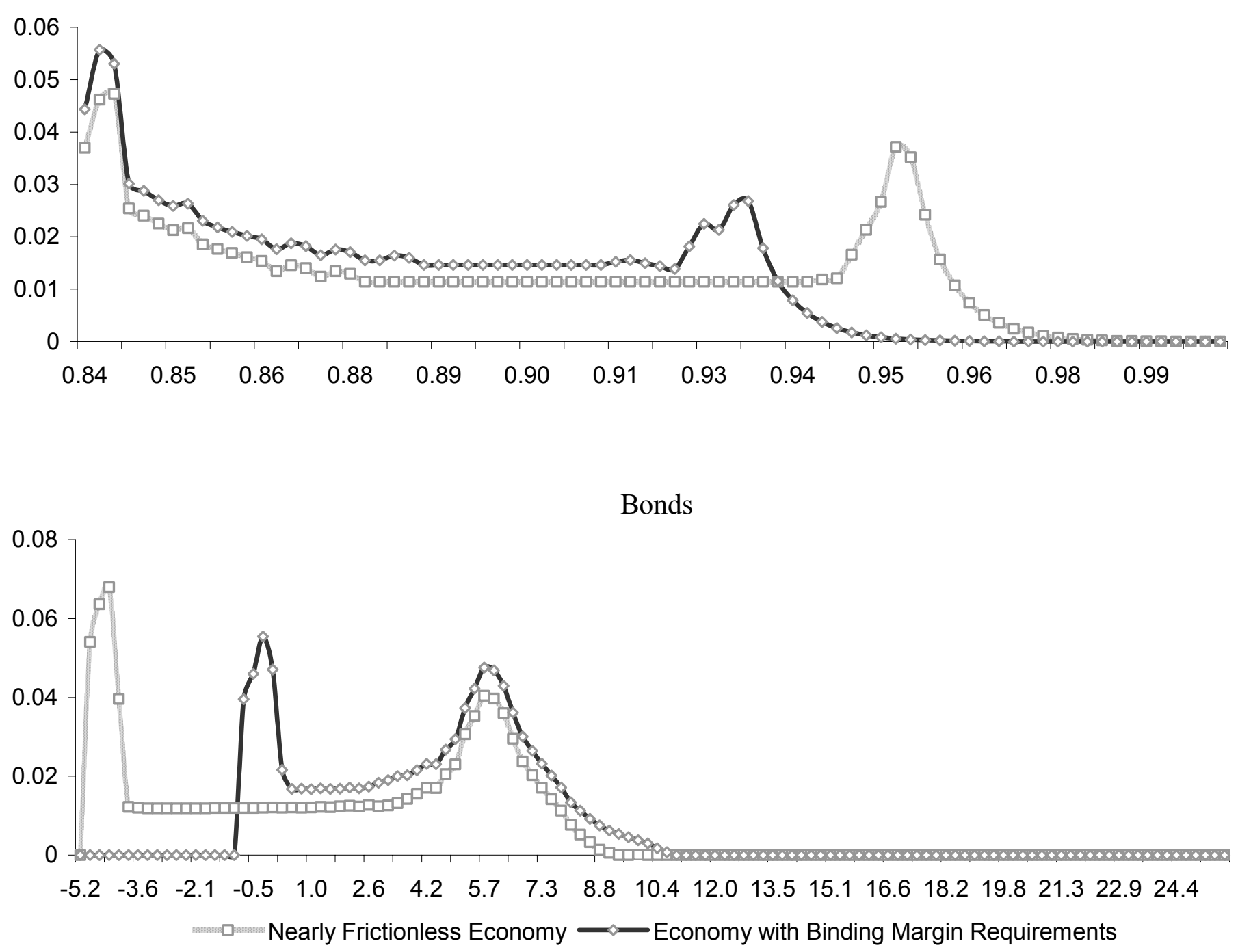
Figure 3. Consumption Impact Effects of a Negative Productivity Shock in the Sudden Stop Region of Equity \& Bonds (percent deviations from long run average)

deviation from mean

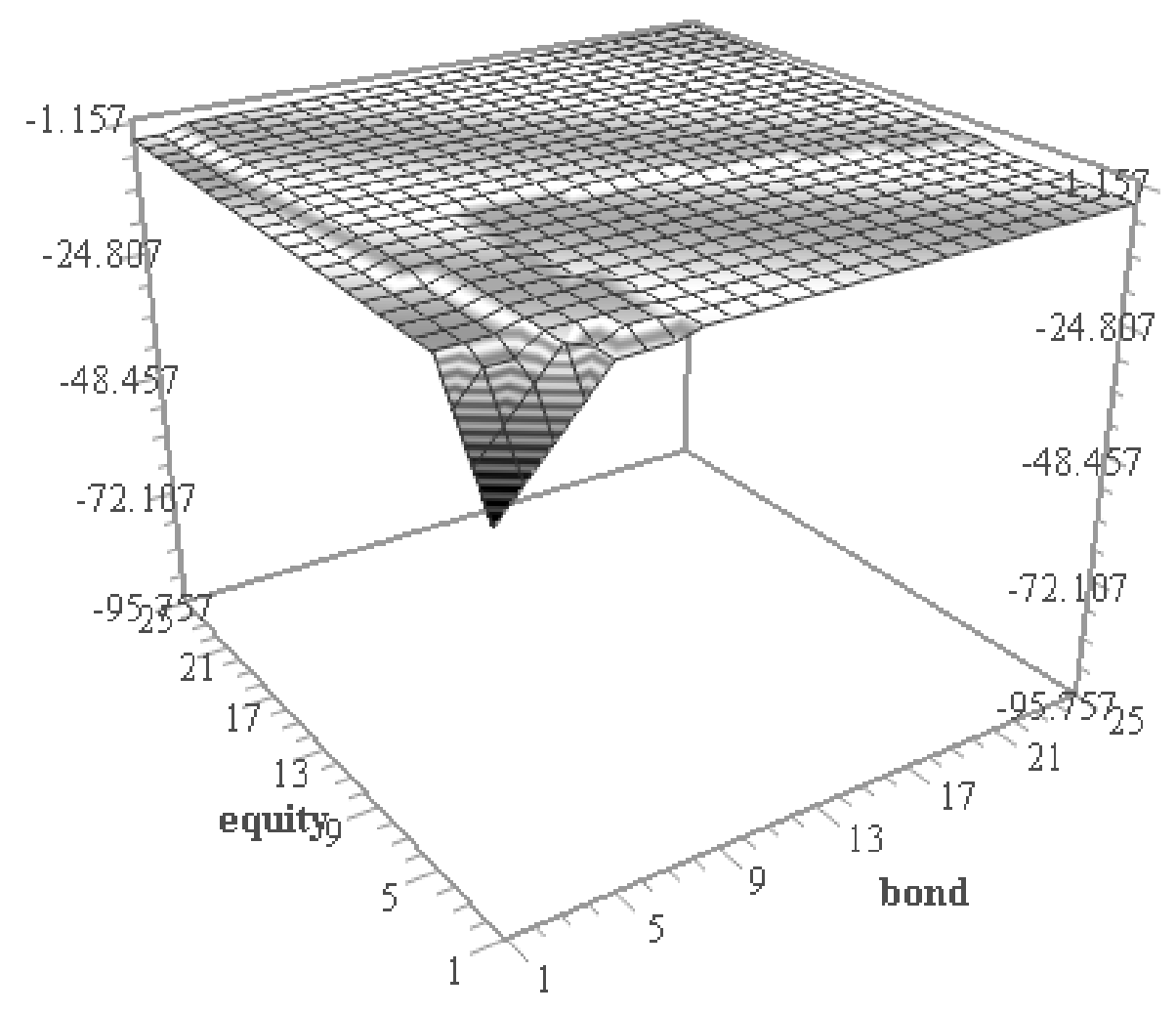

deviation from mean

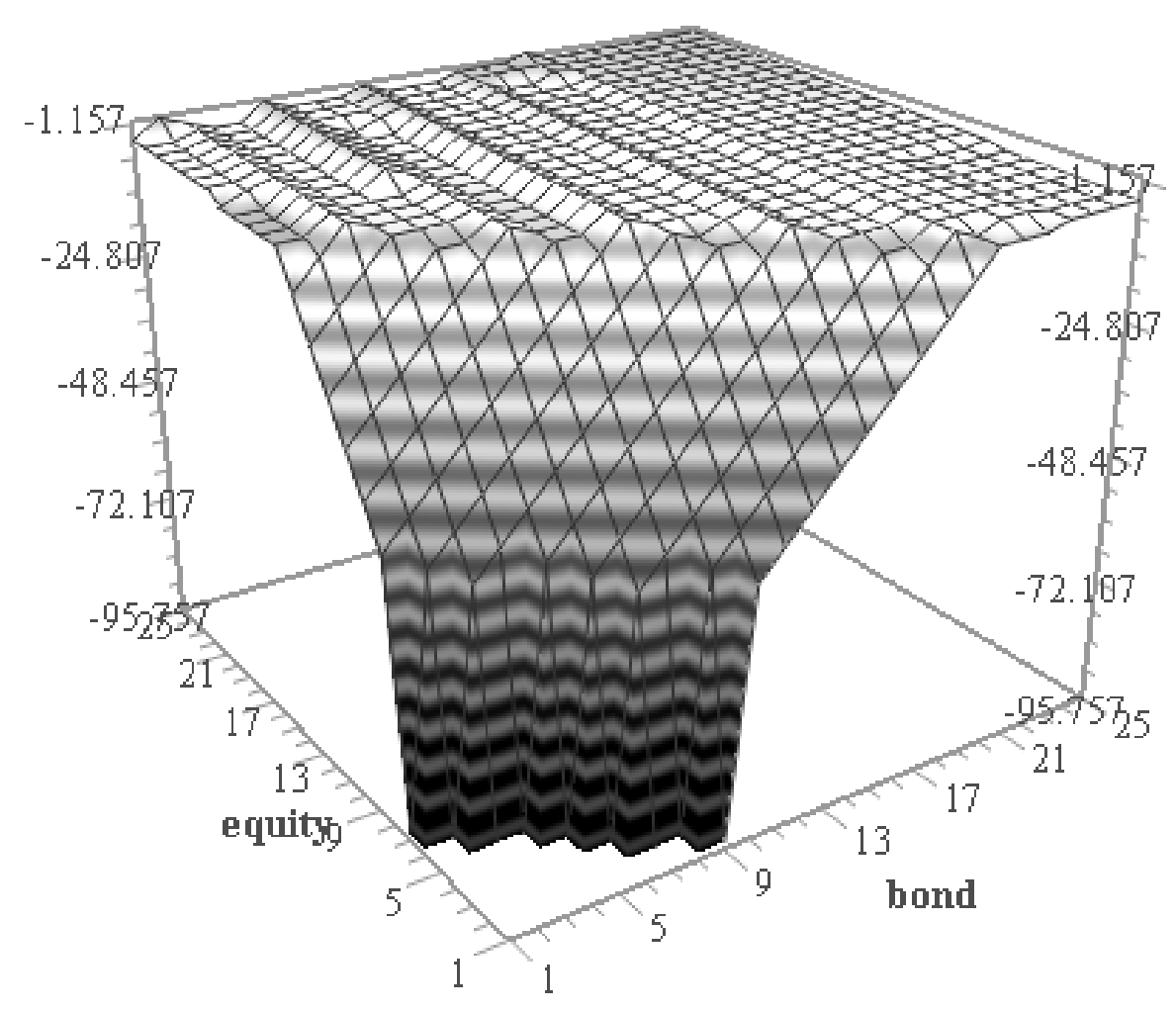

a. Nearly Frictionless Economy

b. Economy with Binding Margin Requirements 
Figure 4. Current Account-GDP Ratio Impact Effects of a Negative Productivity Shock in the Sudden Stop Region of Equity \& Bonds (percentage points difference from long run average)

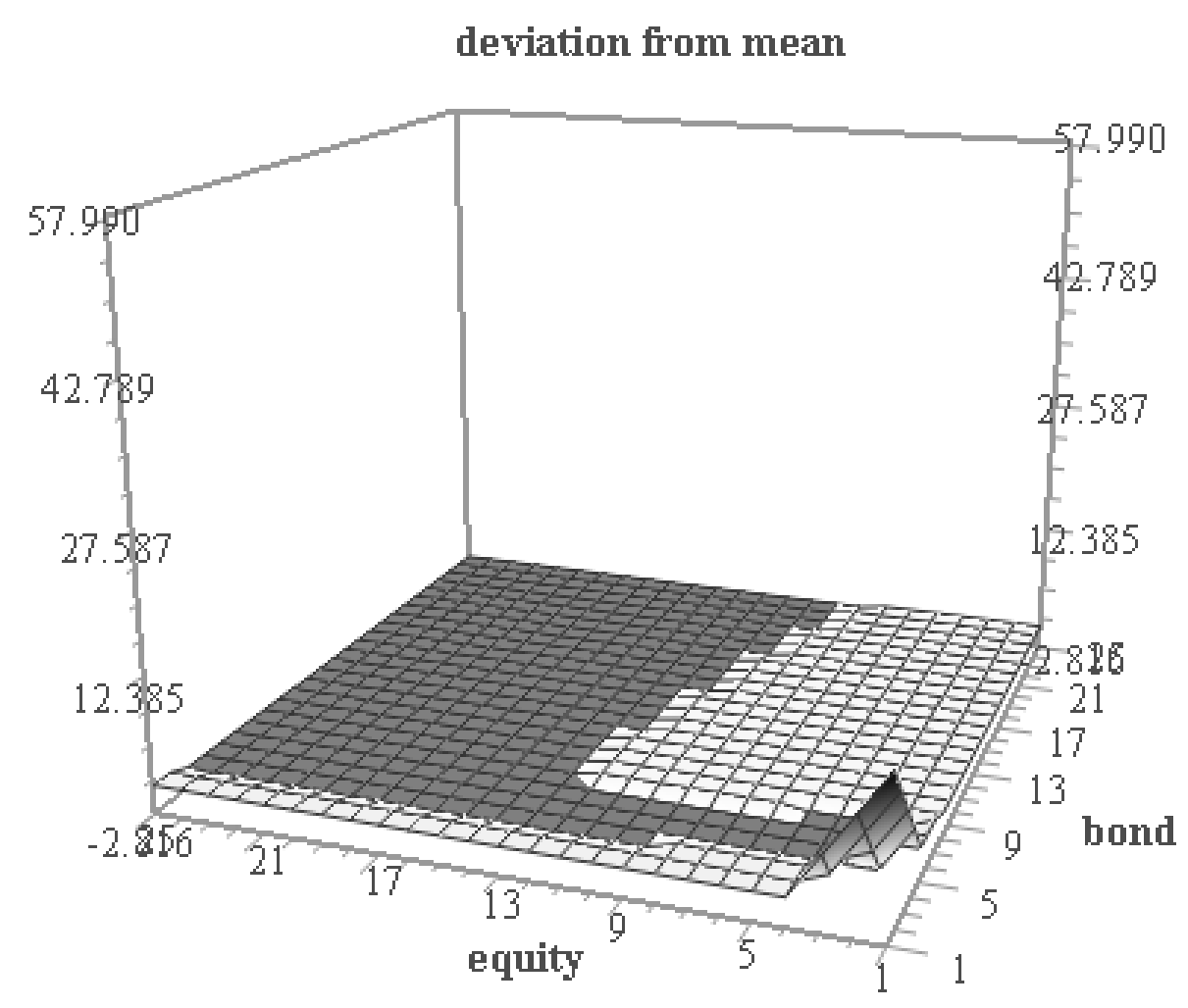

a. Nearly Frictionless Economy

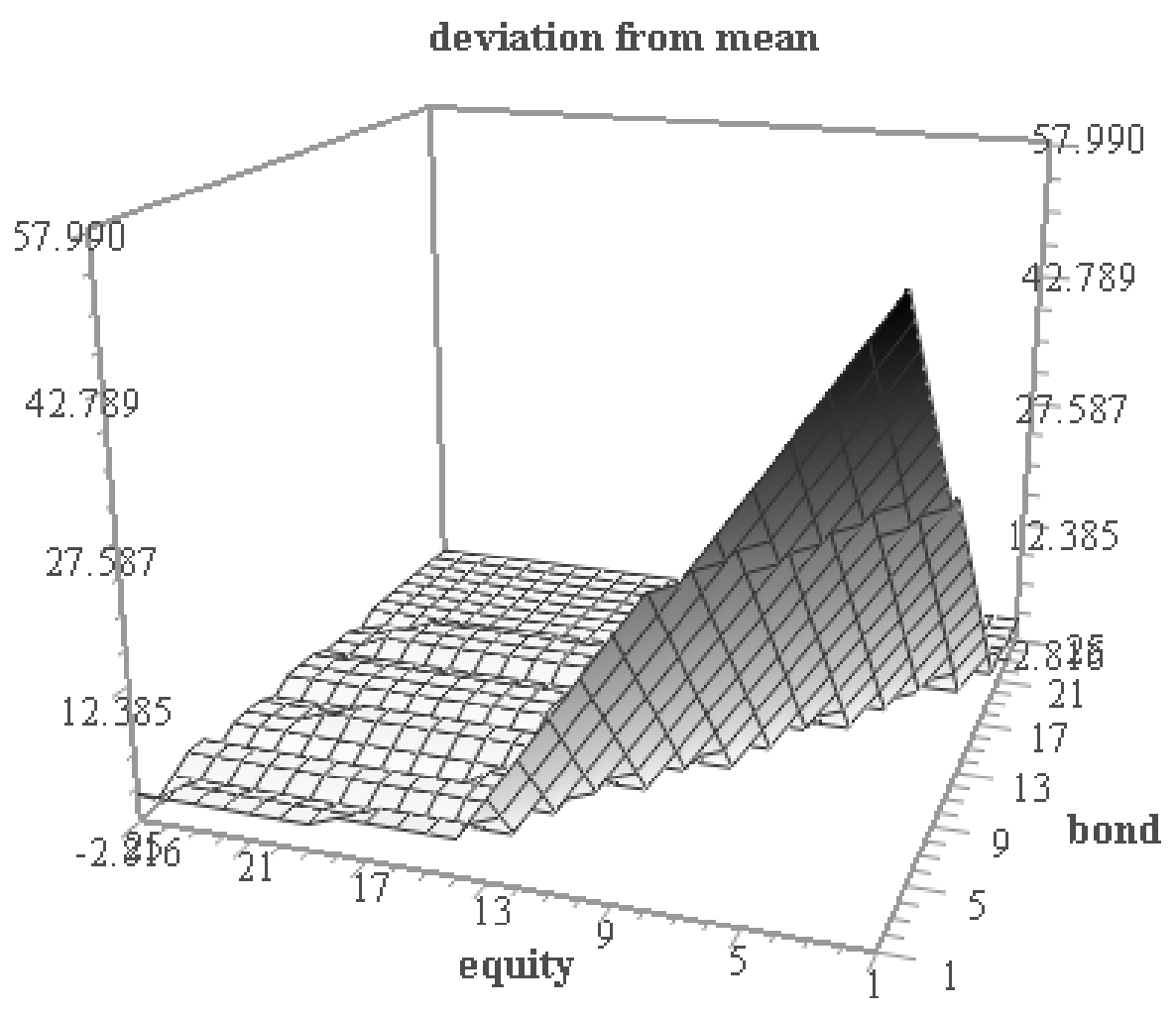

b. Economy with Binding Margin Requirements 
Figure 5. Equity Price Impact Effects of a Negative Productivity Shock in the Sudden Stop Region of Equity \& Bonds (percent deviations from long run average)

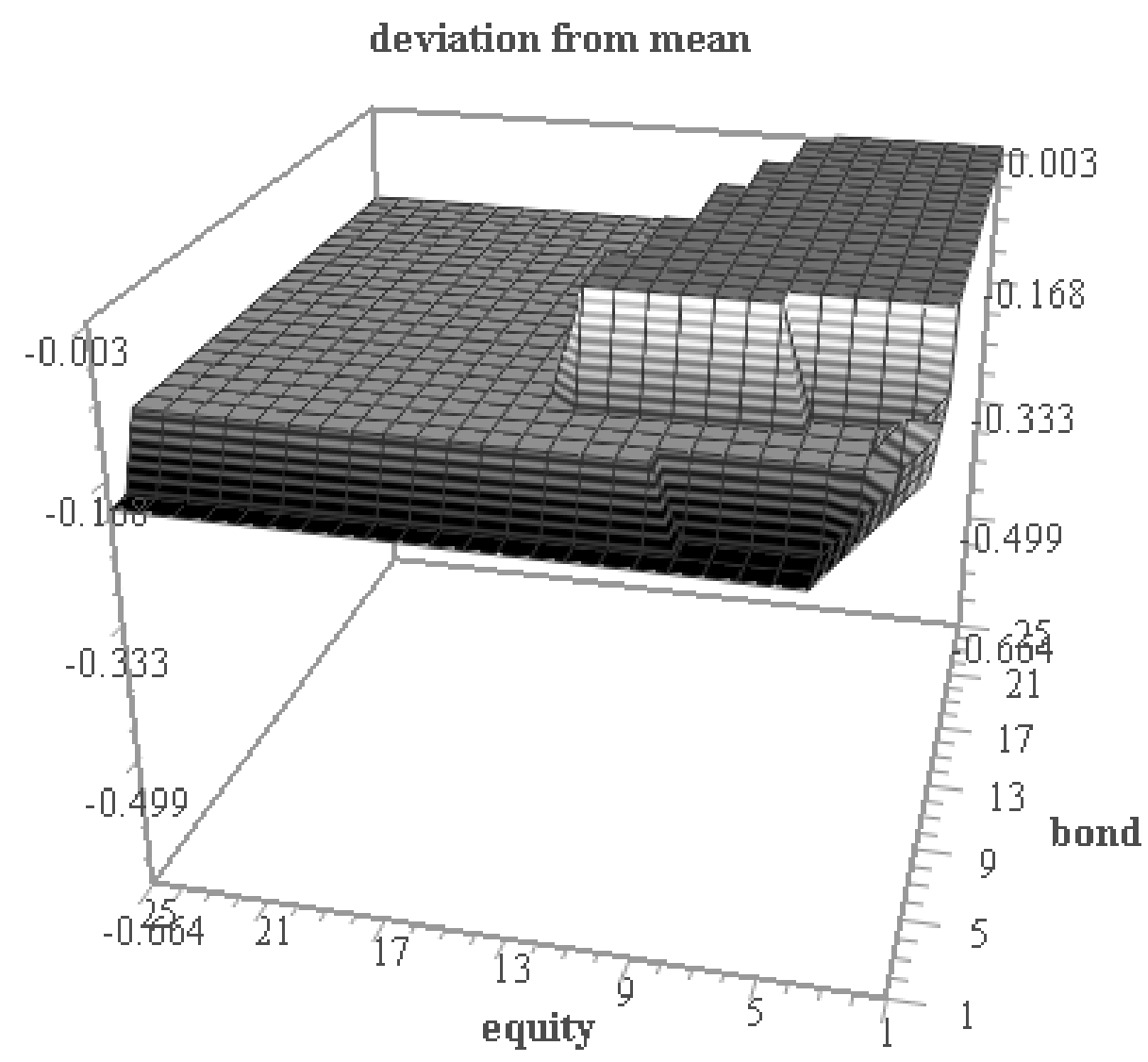

a. Nearly Frictionless Economy

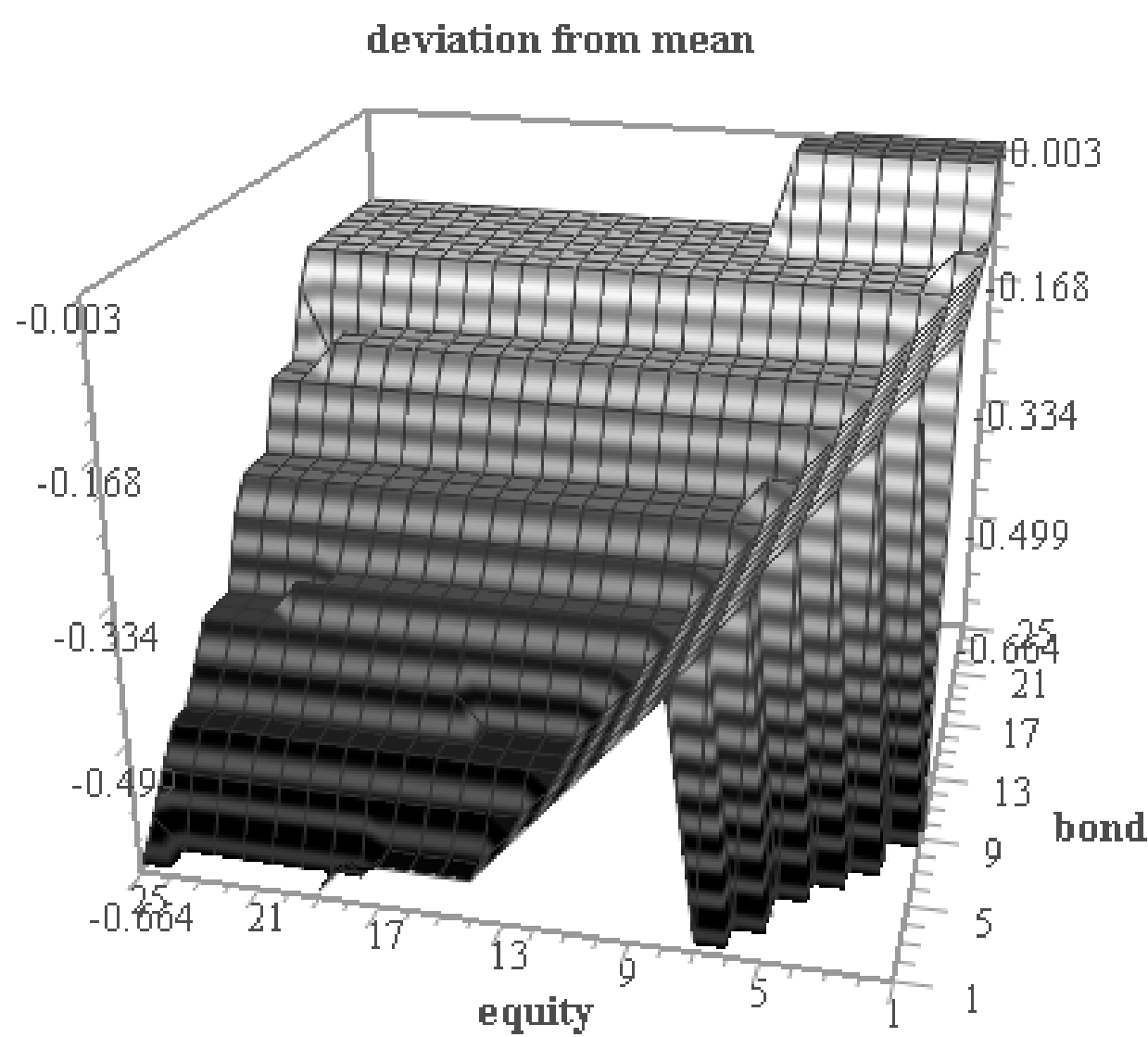

b. Economy with Binding Margin Requirements 
Figure 6. Conditional Responses to a Negative, One-Standard-Deviation Productivity Shock

High Leverage State1/
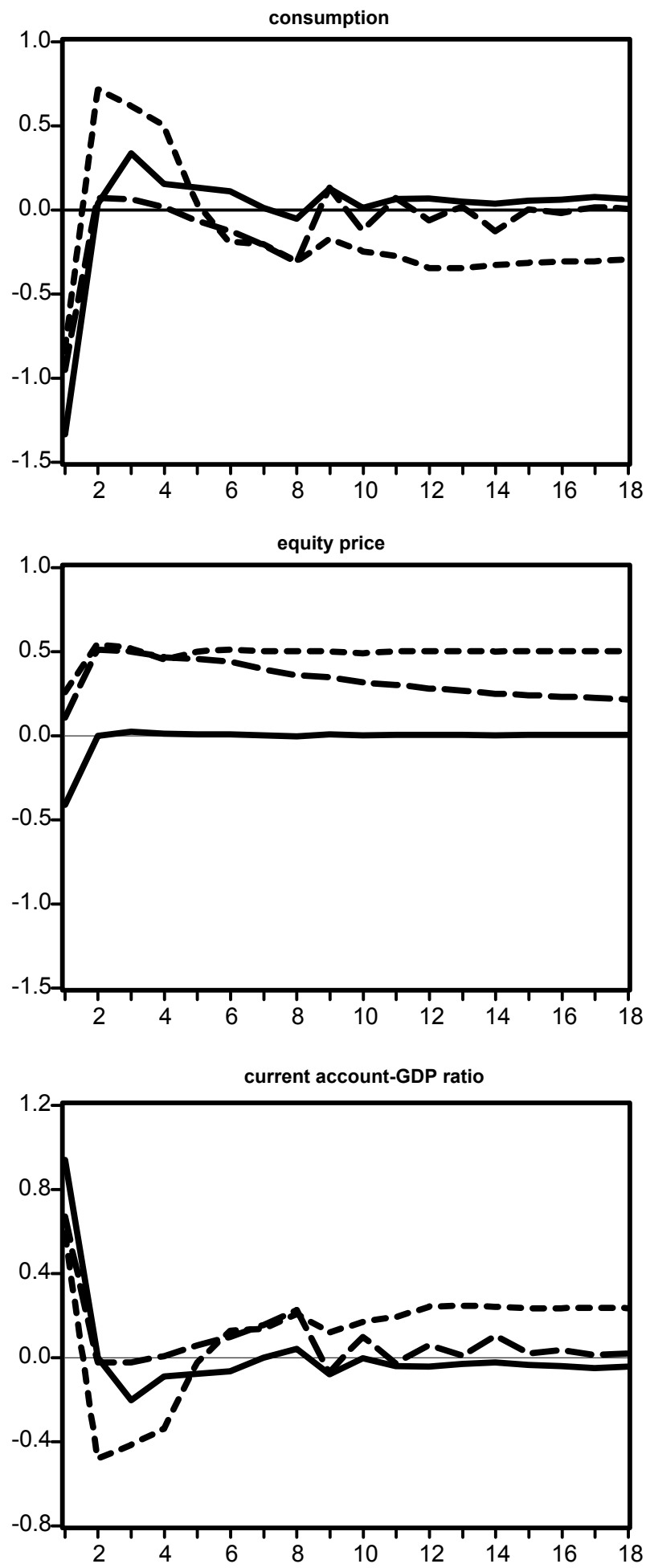

Low Leverage State2/
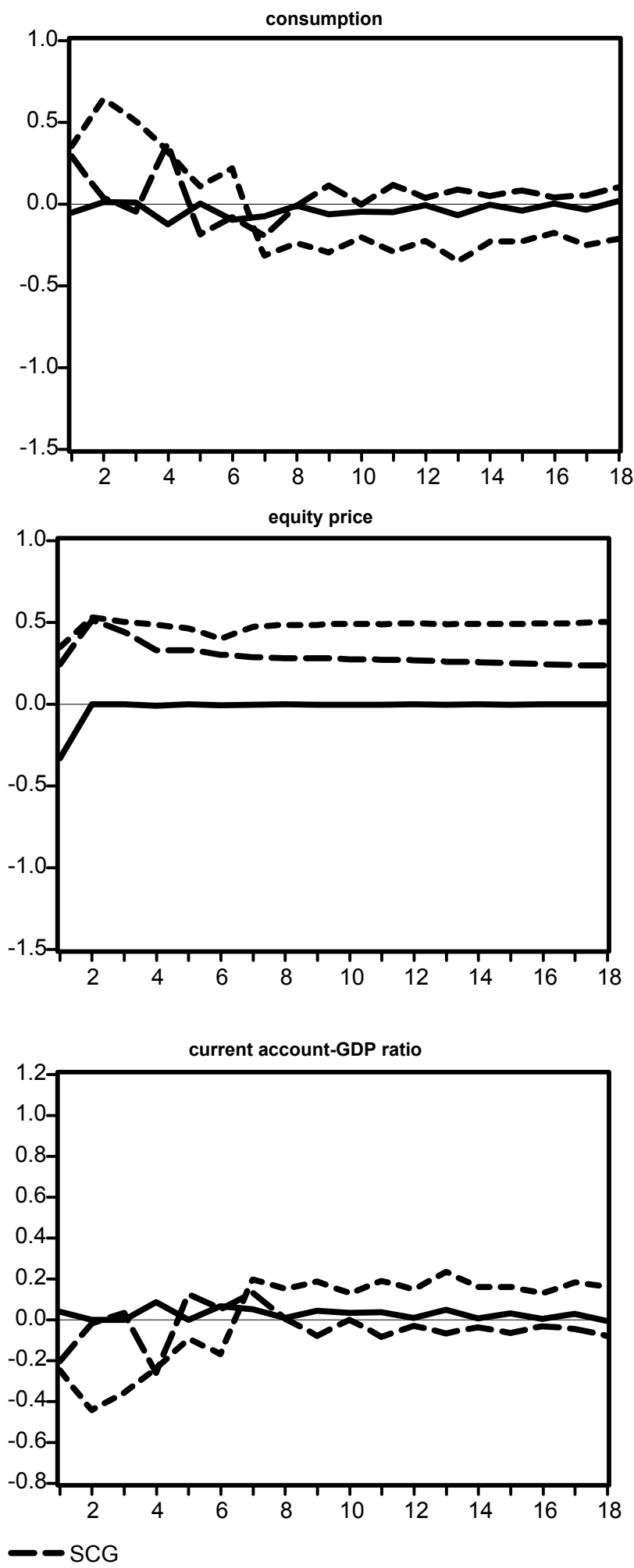

1 / Forecasting functions of each variable's equilibrium Markov process conditional on initial states $\alpha=0.938$ and $\mathrm{b}=-4.68$, which imply a leverage ratio of 0.029 and a debt/GDP ratio of 0.597 .

2 / Forecasting functions of each variable's equilibrium Markov process conditional on initial states $\alpha=0.938$ and $b=-3.38$, which imply a leverage ratio of 0.021 and a debt/GDP ratio of 0.434 . 
Figure 7. Ergodic Distributions of Domestic Equity and Bond Holdings in NSCG and SCG Economies

\section{Domestic Equity}

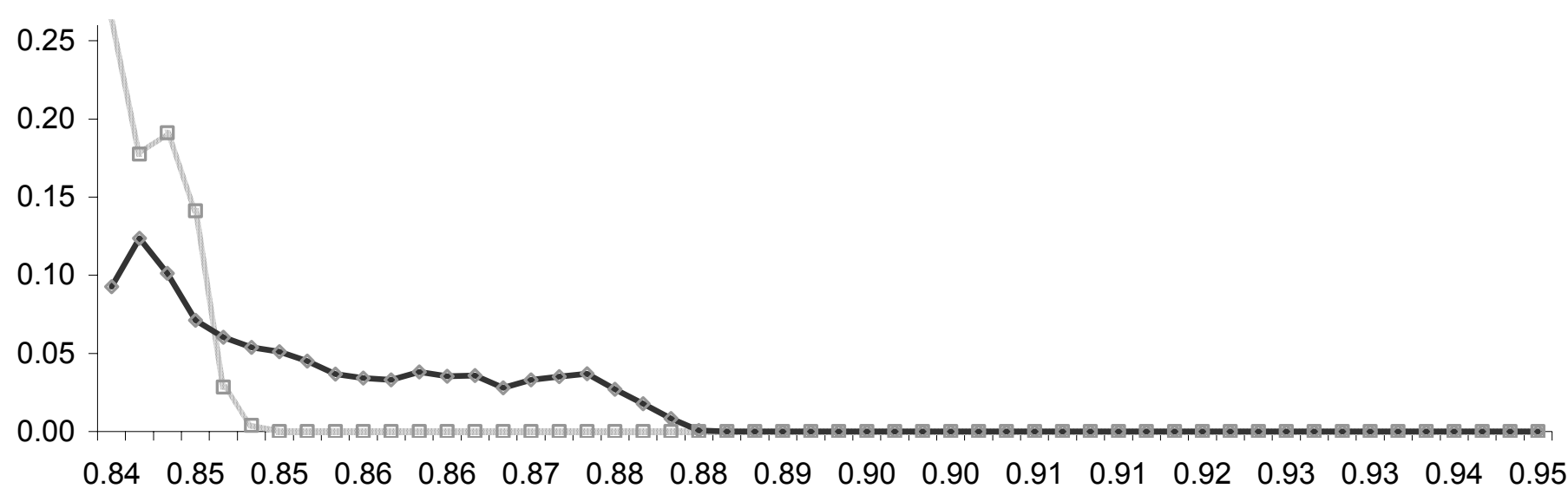

Bonds

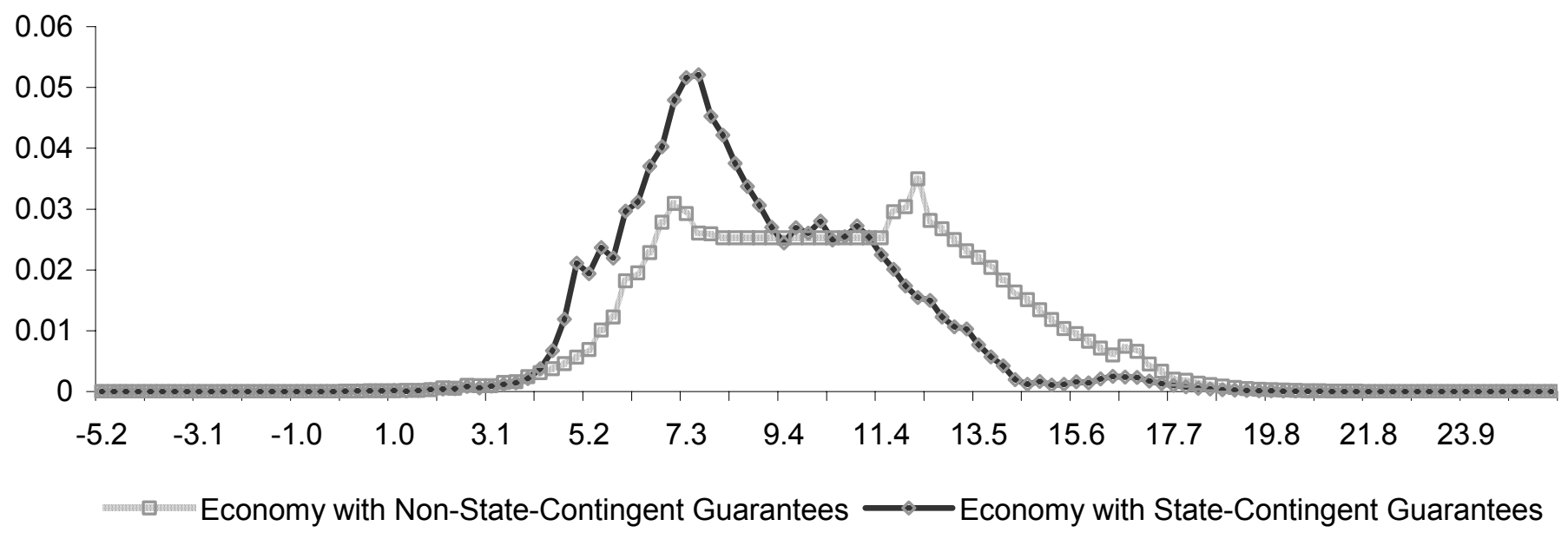


Figure 8. Equity Pricing Function in the Low Productivity State

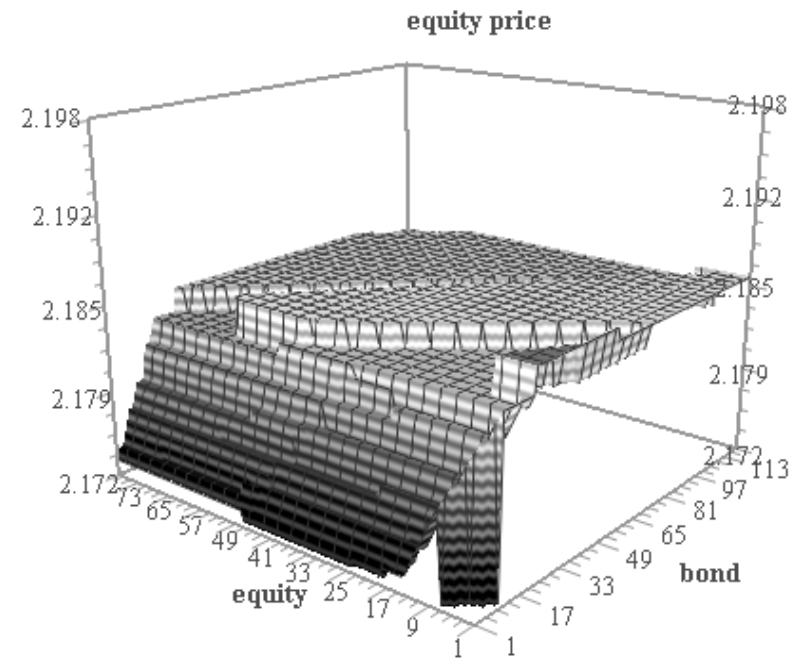

a. Economy with Binding Margin Requirements equity price

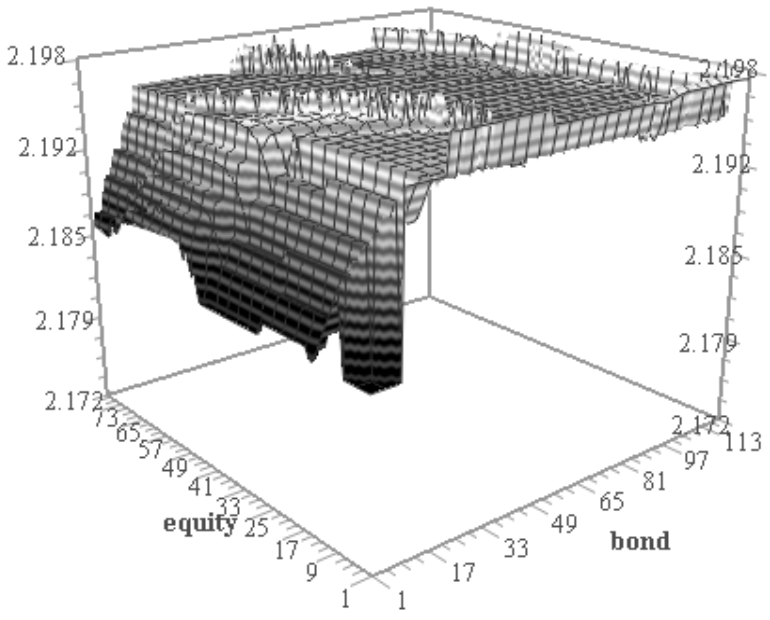

b. Economy with Non-State-Contingent Guarantees

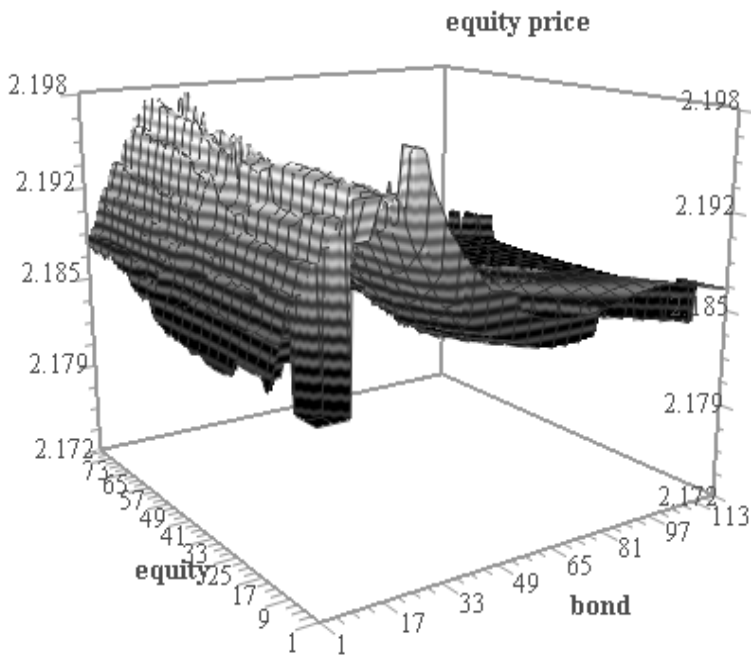

c. Economy with State-Contingent Guarantees 